\title{
REVIEW
}

Open Access

\section{Considering the societal perspective in economic evaluations: a systematic review in the case of depression}

Juliane Andrea Duevel ${ }^{1 *}$ (D), Lena Hasemann ${ }^{1}$, Luz María Peña-Longobardo², Beatriz Rodríguez-Sánchez 2,3, Isaac Aranda-Reneo ${ }^{4}$, Juan Oliva-Moreno ${ }^{2}$, Julio López-Bastida ${ }^{5}$ and Wolfgang Greiner ${ }^{1}$

\begin{abstract}
Background: Depressive disorders are associated with a high burden of disease. However, due to the burden posed by the disease on not only the sufferers, but also on their relatives, there is an ongoing debate about which costs to include and, hence, which perspective should be applied. Therefore, the aim of this paper was to examine whether the change between healthcare payer and societal perspective leads to different conclusions of cost-utility analyses in the case of depression.
\end{abstract}

Methods: A systematic literature search was conducted to identify economic evaluations of interventions in depression, launched on Medline and the Cost-Effectiveness Registry of the Tufts University using a ten-year time horizon (2008-2018). In a two-stepped screening process, cost-utility studies were selected by means of specified inclusion and exclusion criteria. Subsequently, relevant findings was extracted and, if not fully stated, calculated by the authors of this work.

Results: Overall, 53 articles with 92 complete economic evaluations, reporting costs from healthcare payer/provider and societal perspective, were identified. More precisely, 22 estimations (24\%) changed their results regarding the cost-effectiveness quadrant when the societal perspective was included. Furthermore, $5 \%$ of the ICURs resulted in cost-effectiveness regarding the chosen threshold ( $2 \%$ of them became dominant) when societal costs were included. However, another four estimations (4\%) showed the opposite result: these interventions were no longer cost-effective after the inclusion of societal costs.

Conclusions: Summarising the disparities in results and applied methods, the results show that societal costs might alter the conclusions in cost-utility analyses. Hence, the relevance of the perspectives chosen should be taken into account when carrying out an economic evaluation. This systematic review demonstrates that the results of economic evaluations can be affected by different methods available for estimating non-healthcare costs.

Keywords: Cost-utility analysis, CUA, Quality-adjusted life years, QALY, Societal perspective, Incremental cost-utility ratio, ICUR, Direct costs, Indirect costs, Depression

\footnotetext{
*Correspondence: juliane.duevel@uni-bielefeld.de

'AG 5 - Department of Health Economics and Health Care Management, Bielefeld University, School of Public Health, Universitaetsstrasse 25, 33615 Bielefeld, Germany

Full list of author information is available at the end of the article
}

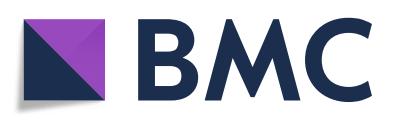

( ) The Author(s). 2020 Open Access This article is licensed under a Creative Commons Attribution 4.0 International License, which permits use, sharing, adaptation, distribution and reproduction in any medium or format, as long as you give appropriate credit to the original author(s) and the source, provide a link to the Creative Commons licence, and indicate if changes were made. The images or other third party material in this article are included in the article's Creative Commons licence, unless indicated otherwise in a credit line to the material. If material is not included in the article's Creative Commons licence and your intended use is not permitted by statutory regulation or exceeds the permitted use, you will need to obtain permission directly from the copyright holder. To view a copy of this licence, visit http://creativecommons.org/licenses/by/4.0/. The Creative Commons Public Domain Dedication waiver (http://creativecommons.org/publicdomain/zero/1.0/) applies to the data made available in this article, unless otherwise stated in a credit line to the data. 


\section{Background}

In 2015 depressive disorders affected 322 million people worldwide, making up more than $4.4 \%$ of the world's population, and affecting women (5.1\%) more than men (3.6\%) [1]. Thus, even though different mental disorders can be highlighted, depression is considered as one of the most prominent mental disorders, as it is ranked fourth in the top ten causes with the largest amount of years lived with disability in Europe [2]. The disease not only causes high levels of distress and negative effects in those who suffer from it, even leading to early retirement or premature mortality, but also in their relatives, making it a growing public health issue worldwide [3, 4].

The prevalence of depression varies slightly by age with almost $10 \%$ of young adults and more than $11 \%$ of adolescents [5]. This results in several challenges concerning the individual productivity and work ability leading to a downward spiral of unemployment and financial burdens $[6,7]$. To ease the symptoms of depression, many effective interventions and therapeutic approaches, such as cognitive therapy or medication, are available. However, especially antidepressants can cause various side effects [8]. Furthermore, due to the underestimation of the disease prevalence and possible concerns about the associated costs, the adverse effects of medication and stigmatization, many people suffering from depression remain without any treatment [9]. Besides this, depressive disorders are strongly associated with stigmatization. More precisely, evidence suggests that public stigma, defined as opinions about personal beliefs of what most people think, is (i) positively related to self-stigma and negatively associated with help-seeking for mental health problems [10], (ii) contributes to treatment discontinuity, and (iii) leads to poorer quality of life, self-esteem and worsened health status [11]. Consequently, the analysis of stigma effects and its economic consequences has led to an increasing interest in the existing literature [10], showing that stigma and discrimination related to mental health problems might lead to adverse economic effects, as it negatively affects employment, income and healthcare costs [12]. Moreover, antistigma campaigns for people with mental health problems have been proved to be a cost-effective alternative [13].

Taking into account all mentioned before, there is a growing public health interest in the economic effects of depression by a higher use of healthcare services (which range from $508 €$ to $24,069 €$ ) as well as vast labour productivity losses (ranging from $1963 €$ to $27,364 €$ per person per year) [14]. Across 28 European countries, the weight of societal costs can amount for more than $64 \%$ of the total economic burden of depression, with 76 billion euros in terms of losses related to premature mortality and morbidity [15]. The relevance of such costs has been confirmed in country-specific populations, where productivity losses represented half of the economic burden of depression [16].

Within this framework, economic evaluations are useful tools that can help decision-makers to prioritize healthcare interventions or policies in order to achieve not only improvements in health, but also ensuring the financial sustainability of public health systems. Particularly, the economic evaluations carried out in the field of depression have been performed in order to prevent depression [17], improve treatment adherence [16] or compare alternative treatments or interventions [18]. In spite of the existing amount of literature, comparability of economic evaluations poses several challenges $[19,20]$. One of the main reasons is the selection of the most appropriate perspective [21]. Taking into account the importance of non-healthcare costs, it seems to be necessary to focus on encouraging their inclusion in any economic evaluation as well as emphasizing its role, as it has been done in other areas [22]. However, to the best of our knowledge, there is no evidence in the field of depression that has assessed the relevance of including or excluding costs beyond the healthcare ones. Therefore, the main aim of this paper is to analyse the role played by non-healthcare costs (labour productivity loss and/or informal care costs) in the economic evaluations carried out in any intervention for people with depression. More precisely, we would determine whether the inclusion/exclusion of societal costs could alter the results and conclusions of the economic evaluations in any intervention for such target population.

\section{Method}

Data source and search strategy

A systematic literature review was performed with the aim of identifying economic evaluations of any intervention in depression, taking into account the PRISMA methodology. It has not been prospectively registered anywhere. To identify economic evaluations of any intervention in depression, the search strategy was conducted in Medline using the following key words: "cost-benefit analysis" OR "quality adjusted life year" OR "cost-benefit" OR "economic evaluation" OR "cost-effectiveness" OR "cost-utility" OR "economic analysis" AND "depression" OR "depress", whereby MeSH terms and natural key words in titles and abstracts were combined. In order to ensure the sensitivity of the strategy, we searched for "depression" in the Cost-Effectiveness Analysis (CEA) Registry from the Tufts University. This publicly available comprehensive database uses a formalized review process to identify original economic evaluations containing cost-utility analysis (CUA) and to provide detailed information on these studies [23]. Both search strategies were limited to a period of 10 years from 30 
November 2008 to 30 November 2018. The studies' eligibility criteria included i) being an original study published in a peer-reviewed scientific journal ii) being an economic evaluation, more precisely a cost-utility analysis or a CEA and CUA, of any intervention related to depression regardless of whether the intervention was performed in patients with depression or to prevent depression; iii) in case of being an economic evaluation in more than one disease (i.e. anxiety), costs for depression were reported separately or it was explicitly stated that a majority of the participants were depressed; iv) including societal costs (informal care costs and/or productivity losses) in the analysis; v) using quality-adjusted life years (QALYs) in CUA vi); providing results separately for each perspective applied (healthcare and societal perspective); vii) and being written in English.

\section{Data extraction}

After removing duplicates, an assessment considering the inclusion and exclusion criteria and data extraction was conducted by LP, BR, JD and LH. While three researchers were responsible for the first revision of titles and abstracts (LP, BR, IA), the full-text screening and data extraction was carried out by JD and $\mathrm{LH}$, and double checked by LP and BR. Whenever there was a disagreement in screening process, the paper was reviewed by a third researcher (WG).

We extracted the following variables from each included study: authors, year of publication, perspective (society or healthcare payer/provider), country, type of intervention (prevention, screening/diagnostic, pharmaceutical therapy, non-pharmaceutical intervention, combined intervention, collaborative care), type of analysis (CUA or CEA/CUA), time horizon, discount rates used for costs and/or outcomes, study design, costs included, currency and type of sensitivity analysis (SA) (deterministic, probabilistic). Moreover, information about the analysis including the incremental costs, incremental QALYs, incremental cost utility ratio (ICUR), authors' conclusions, whether the inclusion of societal costs changed the results or the conclusion about the adoption of the assessed intervention as well as the threshold were excerpted. In case of incomplete or misleading information, original authors were not contacted. To improve the comparability of the results, the incremental costs and ICURs were standardized by inflating the original currency to euros in 2018 prices using the Harmonised index of consumer prices [24]. Supplementary information can be obtained from the authors on request.

The underlying concepts of healthcare and societal costs followed Drummond et al. [25]. Therefore, healthcare costs encompass e.g. intervention costs, outpatient (incl. general practitioners and specialists) and inpatient services, medication and societal service costs. On the contrary, societal costs are defined as lost resources in consequence of absenteeism, presenteeism, premature death and costs of informal care [25]. We focus on the distinction between the healthcare payer/provider perspective and societal perspective. While the healthcare payer perspective includes the aforementioned healthcare costs, the societal perspective further considers societal costs.

\section{Results}

By the initial search, 1273 articles were identified, of which 1263 were found in Medline and additional ten by the Tufts CEA registry. After reviewing all abstracts, 952 studies were excluded as duplicates or did not meet inclusion criteria. Three hundred twenty-one publications remained for the full text screening, of which 268 were excluded because they did not use QALYs (23 articles), four were identified as duplicated or reduced versions of an included publication, in 129 no societal costs were included and 25 did not include a complete economic evaluation or did not focus on depression (64 articles). Furthermore, we identified seven that followed a review design and 16 publications that did not report the perspectives of interest separately. Thus, a total of 53 articles met the full inclusion criteria and were therefore included in this review [26-78] (Fig. 1).

\section{Study characteristics}

The majority of the 53 economic evaluations were carried out in the Netherlands (28\%) [29, 30, 38, 41-43, 49, 51, 54, 57, 67, 71-73, 76] and the United Kingdom (26\%) $[28,33,35,36,44,46,47,50,52,60-62,75,78]$. Five studies derive from Spain $[27,39,63,64,66]$ and four respectively from the United States [45, 48, 68, 69] and Germany [31, 32, 37, 40]. Three studies analysed data from Sweden $[55,56,59]$ and another two from India $[58,77]$. The remaining six studies used data from Japan [65], Greece [53], Canada [74], Belgium [26], Korea [34] and Finland [70].

Concerning the perspective, 22 of the studies (42\%) applied the societal perspective [30, 38, 40-43, 45, 48, 49, 53-57, 59, 63, 66, 67, 69, 71-73, 76]. Eighteen studies conducted an evaluation considering both positions [26-29, $31,32,34,37,39,50,51,58,62,64,65,74,75,77]$ and 12 focused on the healthcare perspective and calculated societal costs separately $[33,35,36,44,46,47,52,60,61,65$, $70,78]$. One study did not explain which perspective was used [68]. Nevertheless, it was possible to extract costs and consequences separately for healthcare and society from the data included in the results table.

Considering the intervention type, $26 \%$ of the studies compared two or more different pharmaceuticals [26, $28,34,36,38,53,55-57,59,62,66,69,70]$, whereby the main part of the articles evaluated non-pharmaceutical interventions such as cognitive behavioural therapy or 


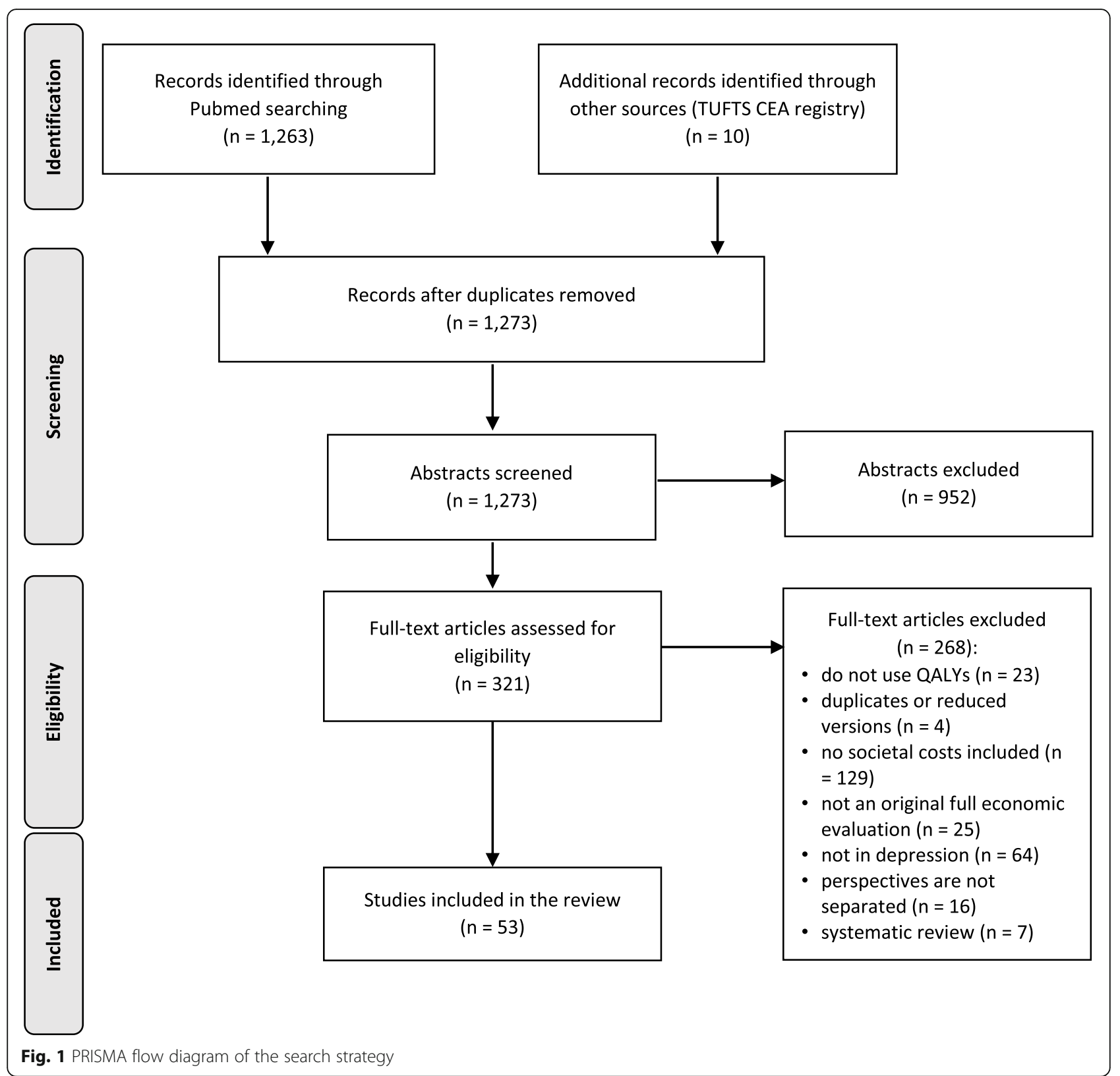

other psycho-educational therapies. Collaborative care interventions were evaluated in eight studies [27, 40, $42-44,49,60,72]$ and seven articles focused on a combination of pharmaceutical and psychological interventions [46, 50, 54, 58, 65, 67, 75]. Preventive approaches $[29,32,39]$ and screening or diagnostic tools $[31,45,48]$ were used in three studies respectively. In almost all cases, standard care or treatment as usual was the comparator, regardless of the individual intervention type.

The majority $(70 \%)$ of the 53 economic evaluation studies included CEA as well as CUA. Regarding the study design, most of the publications reported data from randomized controlled trials (RCT) [27-33, 35,
$38-44,46,47,49-52,54,58,60-64,66,67,69,71-73$, 76-78] and 16 studies used a modelling approach for the calculations $[26,34,36,37,45,48,53,55-57,59,65$, $68,70,74,75]$.

In 16 studies, both aspects of societal costs were included [29-33, 35, 44, 49-51, 58, 68, 71-73, 76]. The other studies used either productivity losses $[26,27,34$, $36-43,45-48,52-57,59,61,63-67,69,70,74,75,77$, $78]$ or costs of informal care only $[28,60,62]$. The approach to estimate societal costs was not always explicitly depicted. When stated, the approach to value productivity losses was almost balanced between the human capital approach $[31-33,37,39,40,46,50,61,63$, 
$64,67,70,73,75,77,78]$ and the friction costs method $[26,30,38,41-43,49,51,52,54,57,71,72,76]$, whereas one study used both [29]. In terms of the friction costs method, the replacement time varied between 123 and 161 days. Regarding informal care given by relatives or friends, most of the studies applied the proxy good method [28-33, 44, 49, 51, 60, 62, 71-73, 76] and only two used the opportunity cost method for their estimations $[35,50]$. A comprehensive overview of the main characteristics relative to the methods and other context of cost estimation used is given in Table 1.

The calculations were verified by SA in almost every study, except one publication [54]. Most of them used a probabilistic SA [27, 30, 31, 33, 38, 40-43, 47, 50, 52, 58, $59,63,71,75-78]$ or a combination of both types (deterministic and probabilistic) of SA [26, 32, 34-36, 39, 44, $48,49,51,53,55,56,60,61,65,69,70,72]$. Thirteen articles evaluated a time horizon of less than 1 year [28, $31,47,55-58,62,64,66,67,69,76]$. Twenty-five monitored the study population for 1 year $[26,27,29,30,32-$ $35,38,41,42,44,46,49,50,54,59,60,63,65,68,70$, $73,77,78]$ and 15 evaluated a larger time horizon within a range from 13 months to lifetime [36, 37, 39, 40, 43, $45,48,51-53,61,71,72,74,75]$. In the latter cases, 11 of these analyses used a discount rate between 3 and $5 \%$ for discounting the costs $[33,36,37,39,45,48,52,53$, $61,71,75]$. However, only four of them discounted both costs and QALYs [36, 52, 61, 75].

\section{Results of economic evaluations}

In 20 of the publications more than one result was calculated leading to a total of 92 individual results [26, 28, $38,41,44,45,49,53,56,57,59,62,63,65,67,68,70$, $71,74,76]$. All stated or obtained results were compiled and compared regarding the two perspectives by focussing on the changes in quadrants and conclusions (see Table 2).

In seven studies, the economic evaluation of the intervention resulted in negative incremental QALYs [30, 38, $41,43,52,65,71]$. Another three studies calculated incremental costs higher than the corresponding national willingness-to-pay threshold per QALY from both perspectives, thus resulting in the intervention not being cost-effective at all $[29,49,54]$. In one of these studies, only the unadjusted intention-to-treat analysis was not cost-effective, while adjusted analysis was cost-effective from the healthcare perspective [49]. Regarding the differences in incremental costs, 19 estimations from 14 studies showed cost savings when societal costs were included [26, 28, 38-40, 42, 44, 53, 57, 59, 60, 62, 65, 73]. However, only two of these results ended up in a decision change concerning the ICUR $[65,73]$. From the 16 studies that explicitly conducted an evaluation from both perspectives, the majority of the studies did not identify a substantial change in the cost-effectiveness of the focused intervention(s) $[26-29,31,32,34,37,39,58,62$, 74, 75, 77]. Nevertheless, 20 single results out of these studies led to lower incremental costs by inclusion of societal costs [26-28, 31, 32, 34, 39, 58, 62, 74, 75, 77]. Irrespective of the perspective of the evaluation, 15 single estimations accounted for increasing incremental costs when societal costs were included $[28,29,33,35-37,45$, $46,50,51,54,62-64,67]$.

From the healthcare perspective, ten out of twelve papers reported that the focused intervention dominated the comparator $[47,61,70]$ or had a positive ICUR $[33,35$, $36,44,46,60,78]$ below the threshold applied. When the societal costs were included, the majority of them showed no relevant changes to the direct costs-results $[35,36,46$, $47,52,61,70,78]$. In two cases, the results changed from the intervention having a positive ICUR below the used threshold to being dominant $[44,60]$. One study demonstrated a conclusion change for both single results from not being cost-effective when adopting the healthcare perspective to highly dominant when societal costs were included [65]. However, one study changed from a positive ICUR to a value markedly above the chosen threshold of 30,000 British pounds with respect to the obtained data from the healthcare perspective [33].

In addition, when the societal perspective was selected, two results changed and became cost-effective compared to the analysis only including direct healthcare costs $[73$, 76]. One of these studies ascertained a complete change from a value high above the willingness-to-pay for one QALY to cost savings when societal costs were included, thus becoming not only cost-effective but also dominant [73]. In that special case the scientists evaluated an augmented cognitive behavioural therapy compared to a computerized cognitive training program in post-stroke depressive patients. Another eight economic estimations out of six studies changed from being below the threshold to dominate the standard care or other comparators [40, $42,53,57,59,73]$. One of the interventions altered from being cost-effective to rise above the threshold when societal costs were included [49]. Further, one study changed in a similar way but results from negative incremental costs and negative incremental QALYs [41]. In most of the single results from the societal perspective, no important changes in terms of being cost-effective were obtained $[45,48,53,55,56,62,67,69,72]$.

Figures 2 and 3 give an overview of main variations in the inflated ICURs from healthcare to societal perspective (Please note, that outliers must be excluded for the visualization.). It can be seen that the inclusion of societal costs led to a wider spread of single values in all directions (see Figs. 2 and 3). 


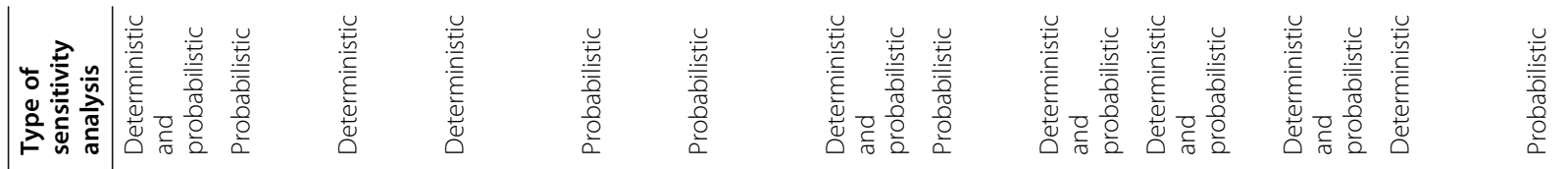

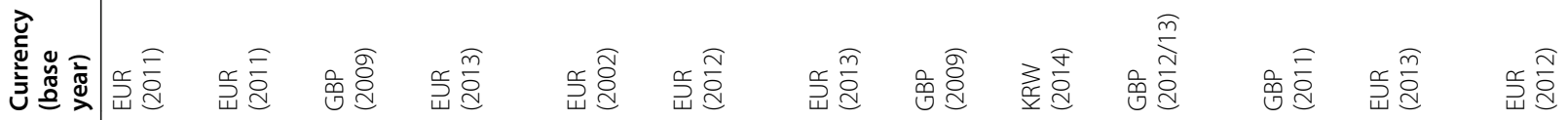
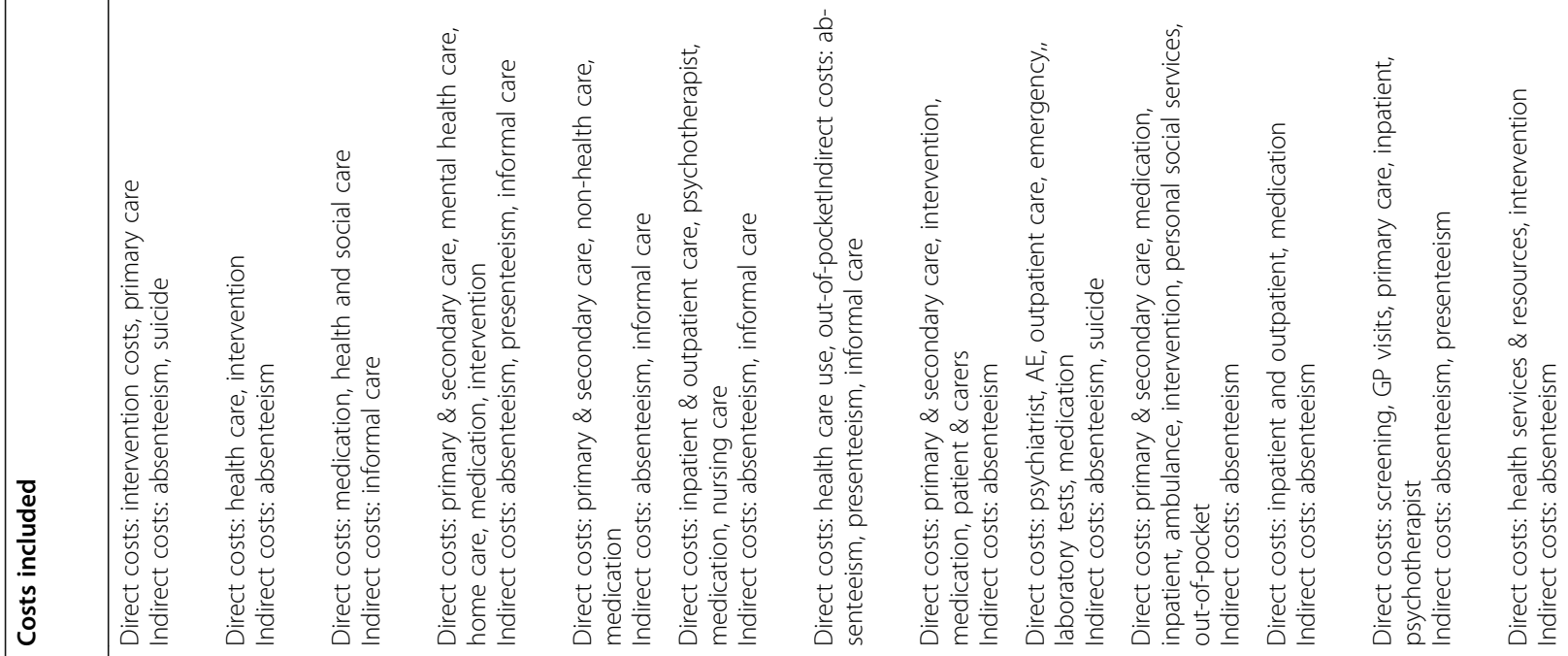

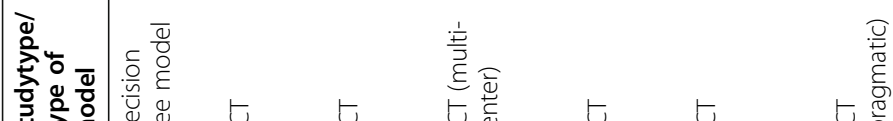

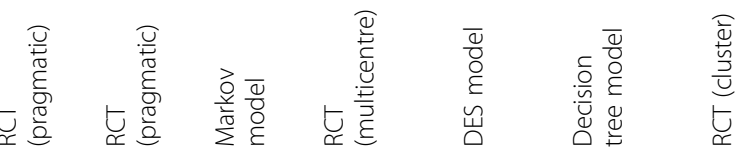

蒙

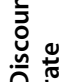

$\frac{y^{2}}{20} \quad \frac{x}{2} \quad \frac{x}{2} \quad \frac{x}{2} \quad \frac{x}{2}$

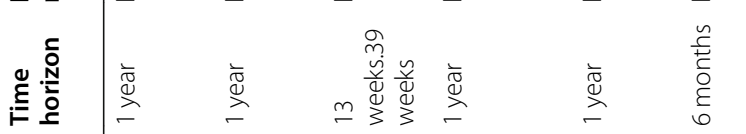

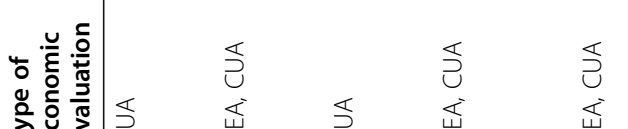

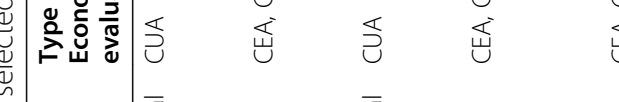

造

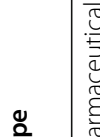

ฆ 


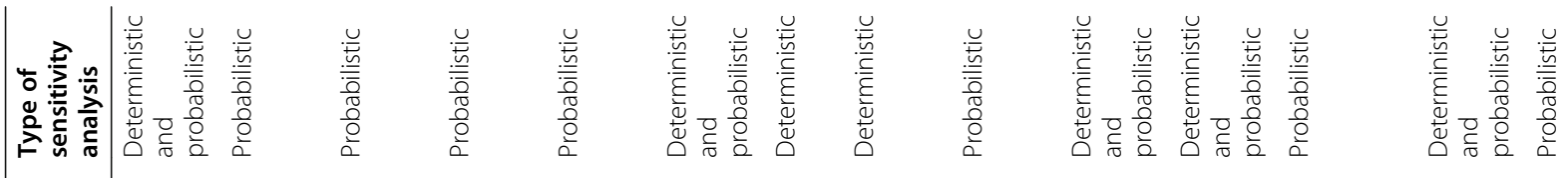

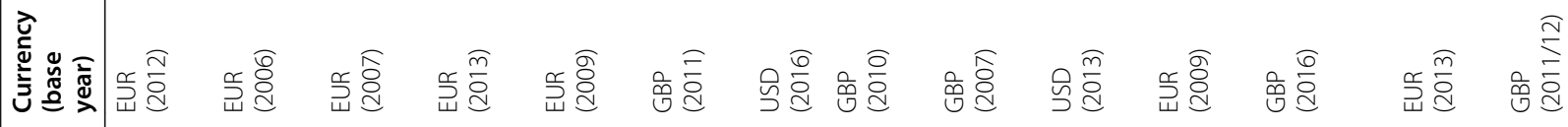
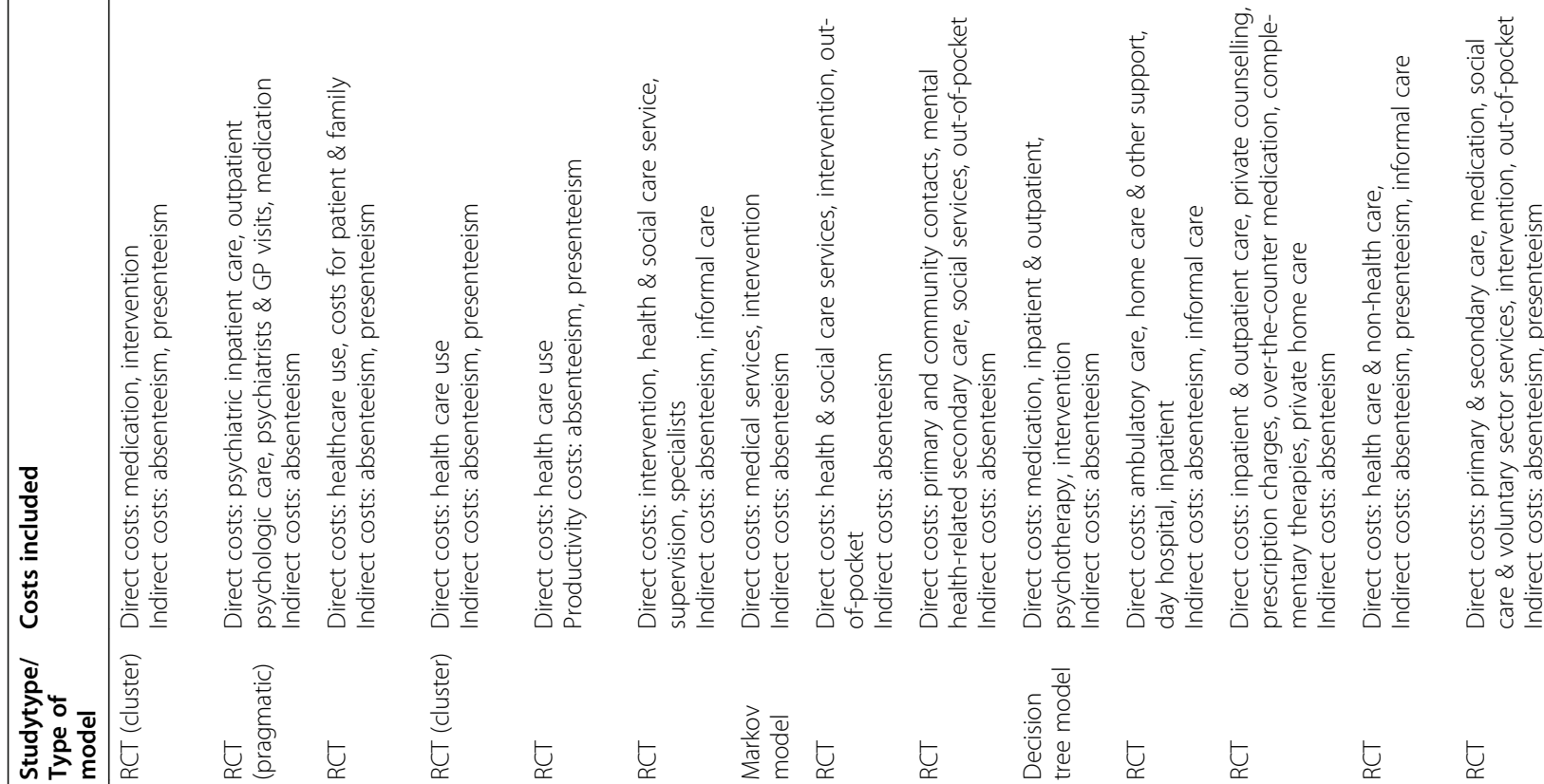

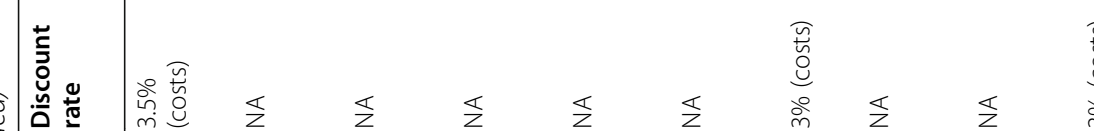

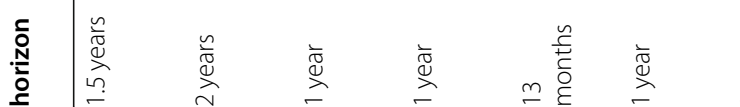

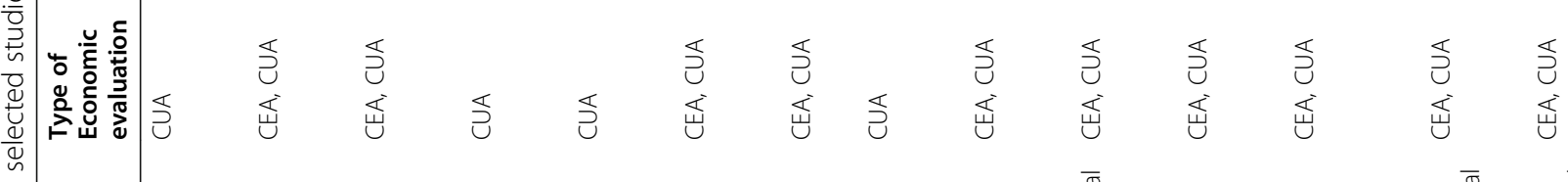

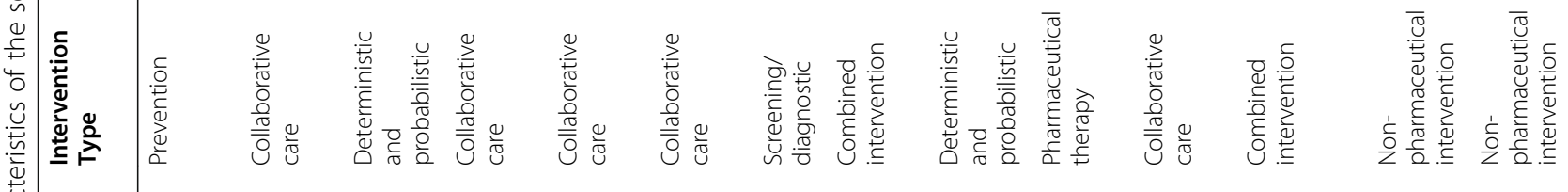

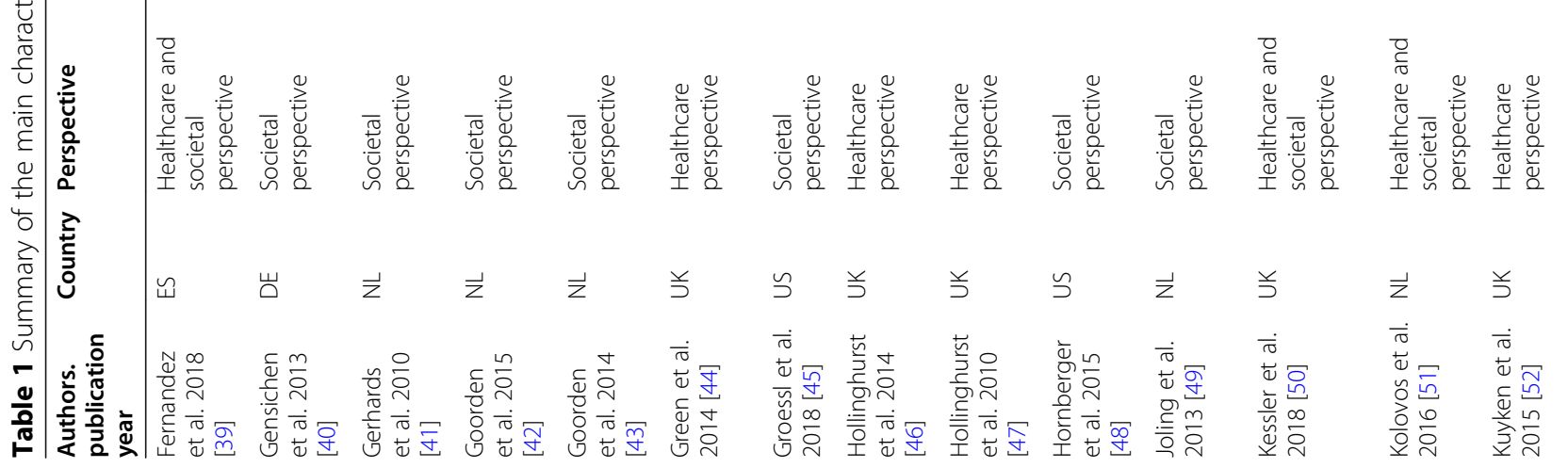




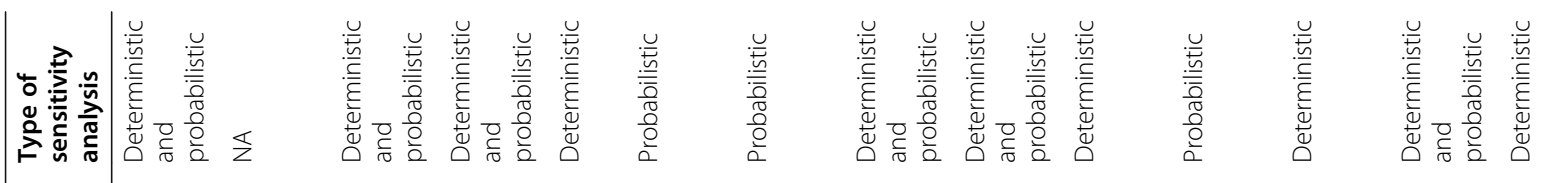

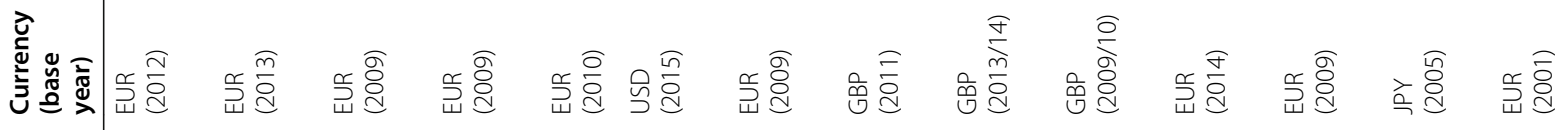

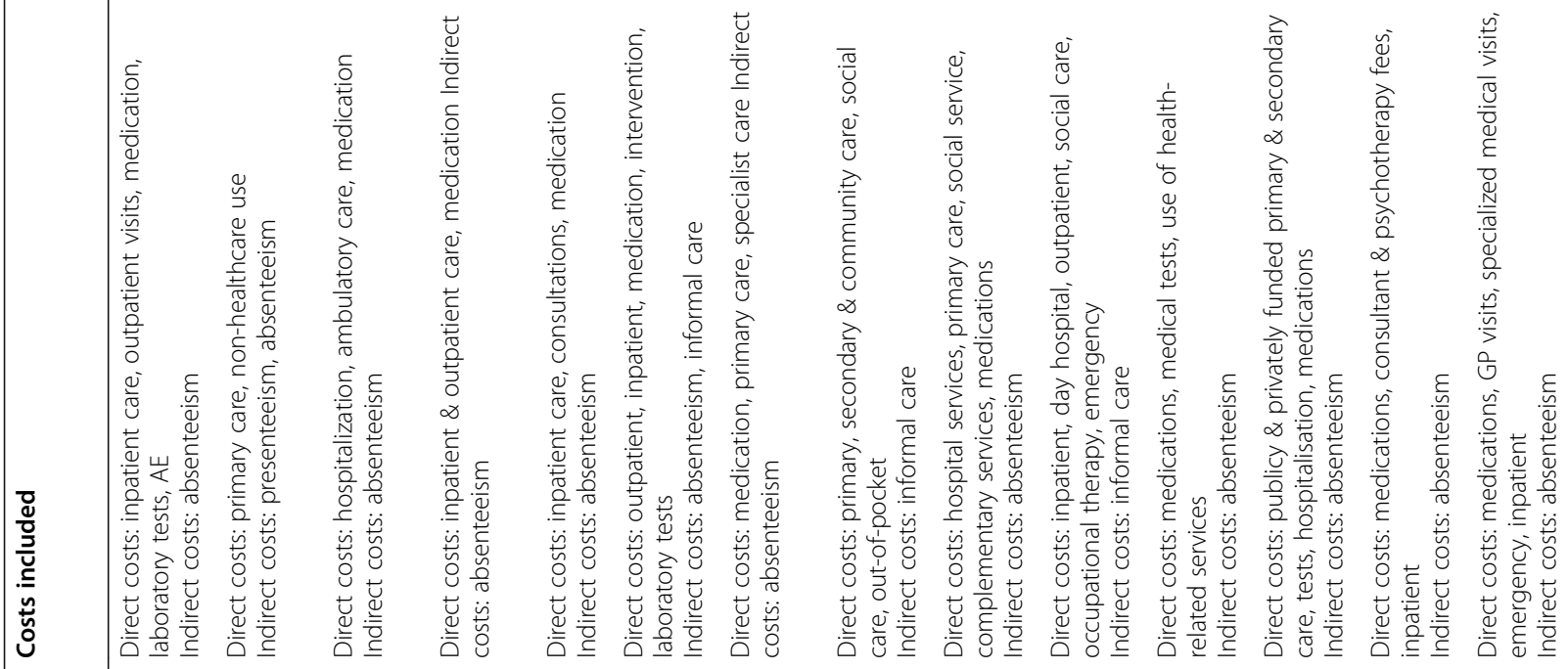

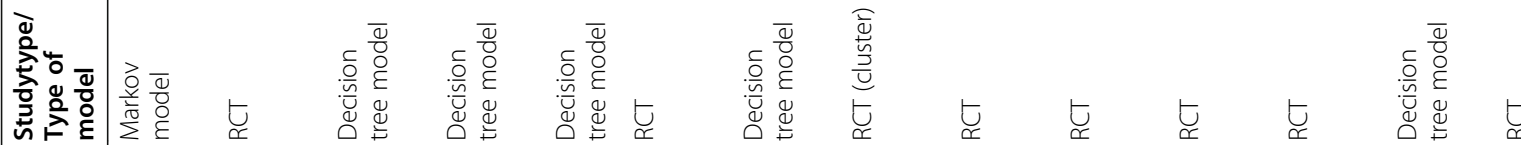

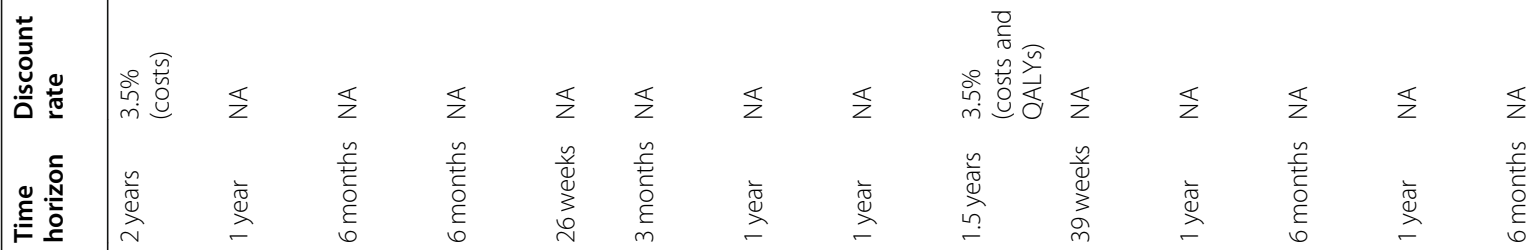

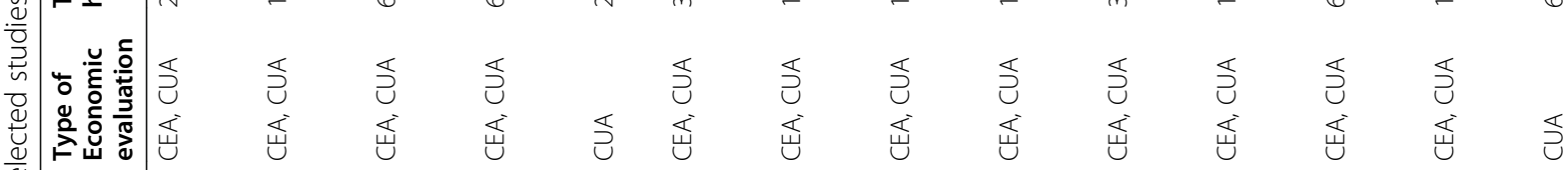

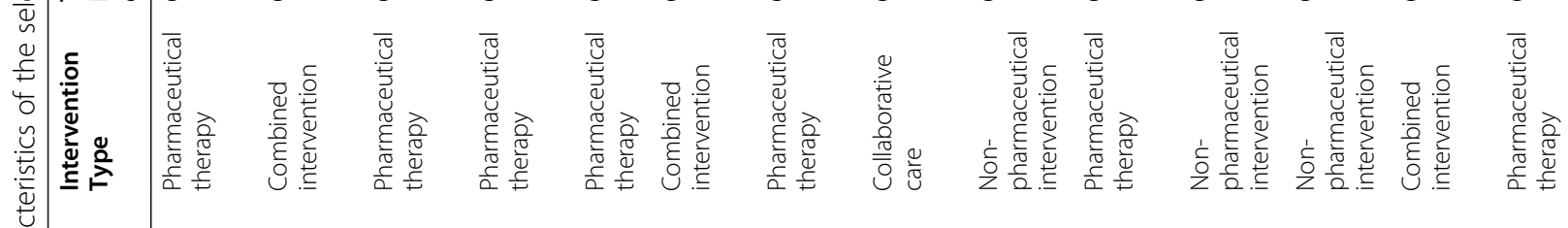

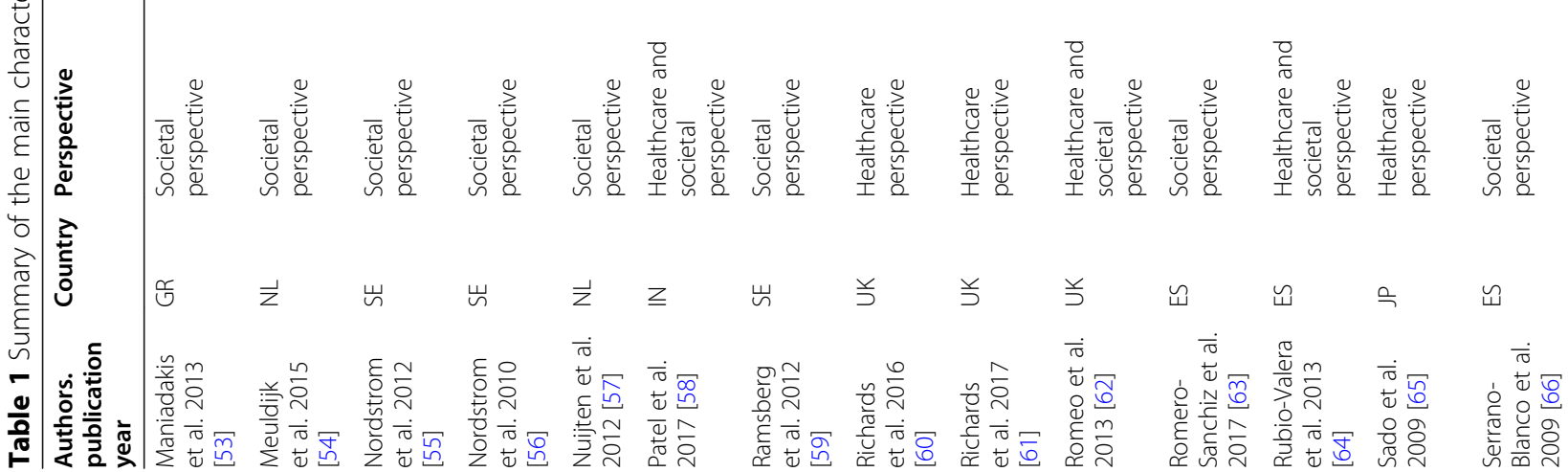




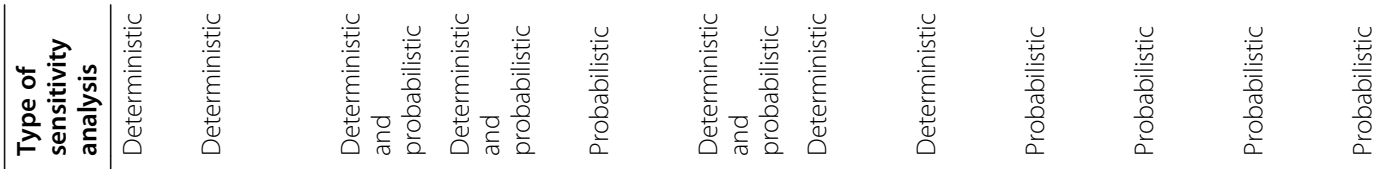

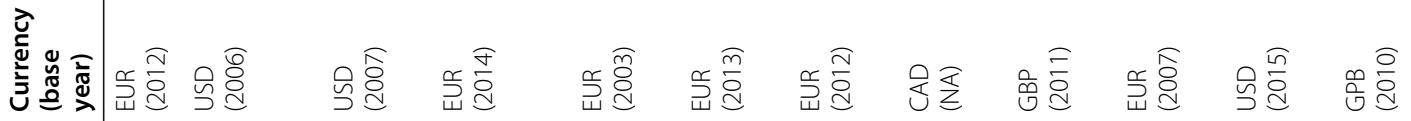

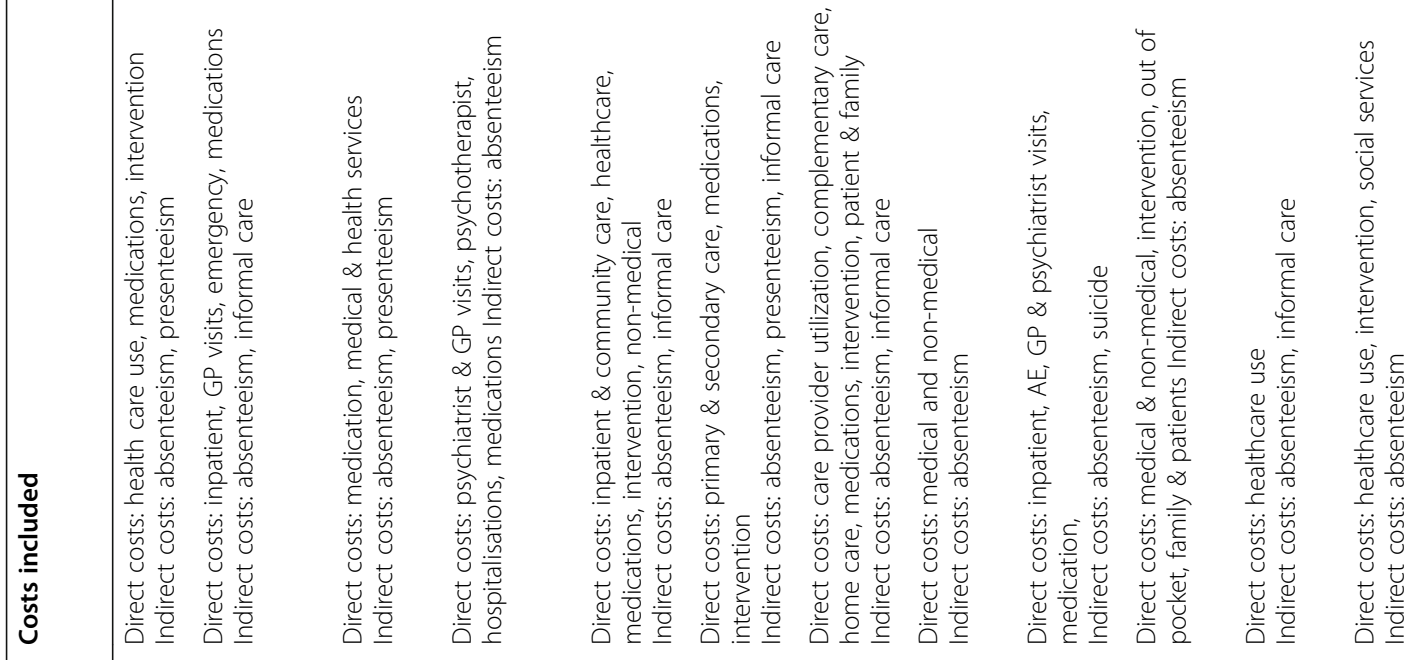

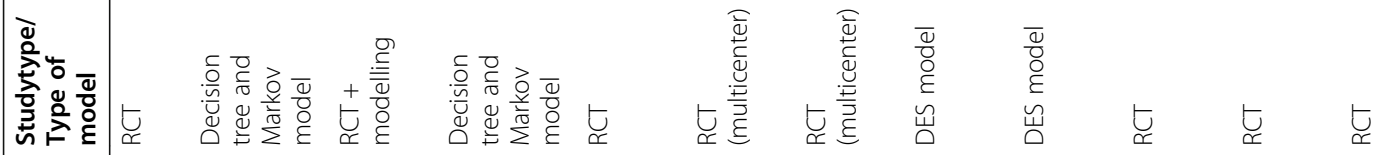

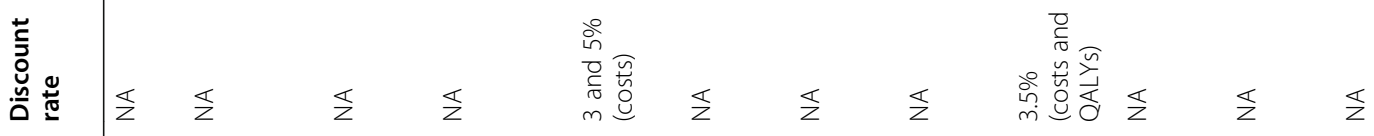

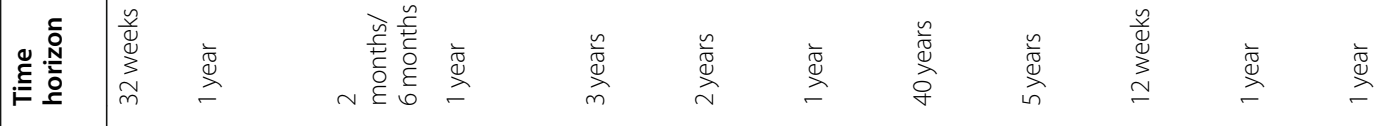

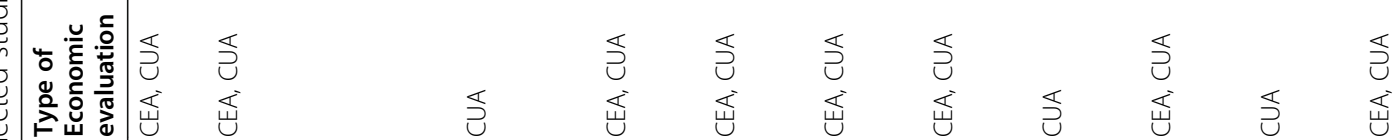

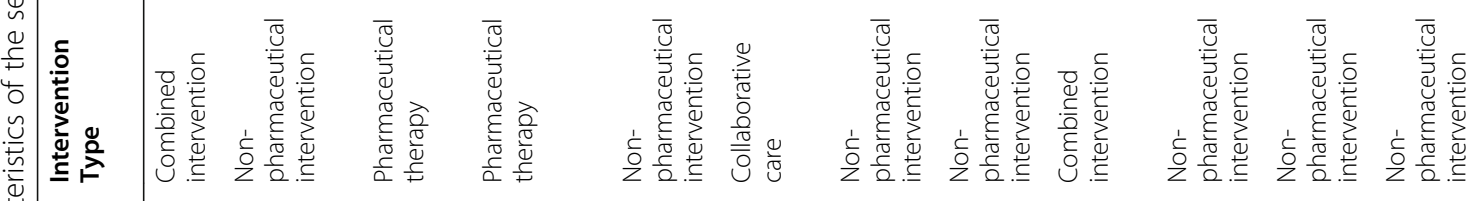

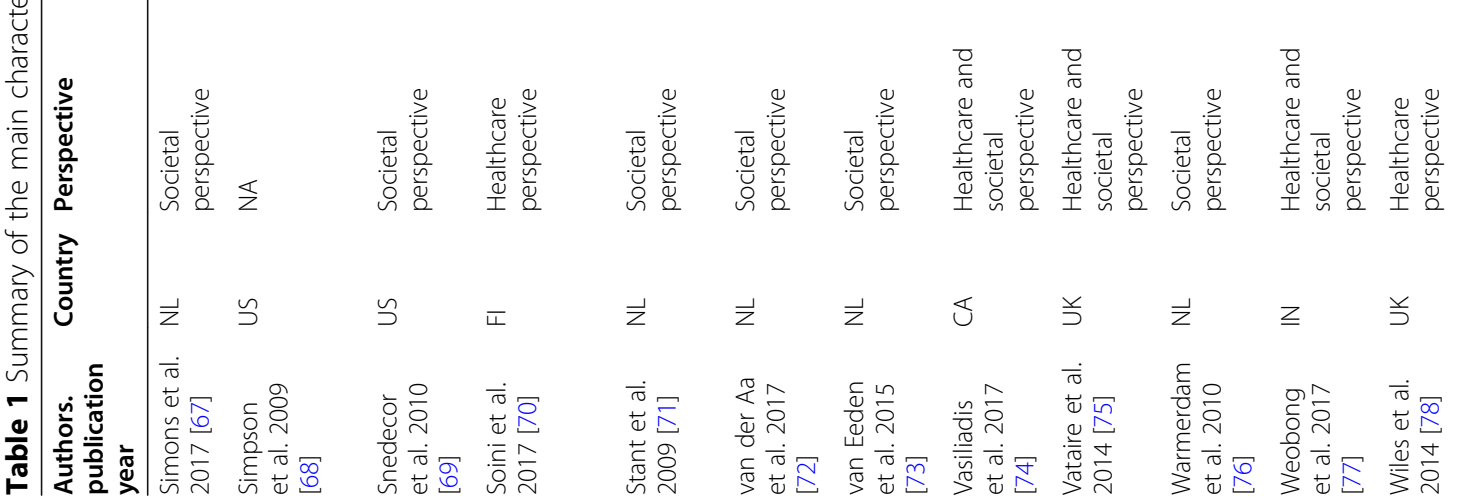




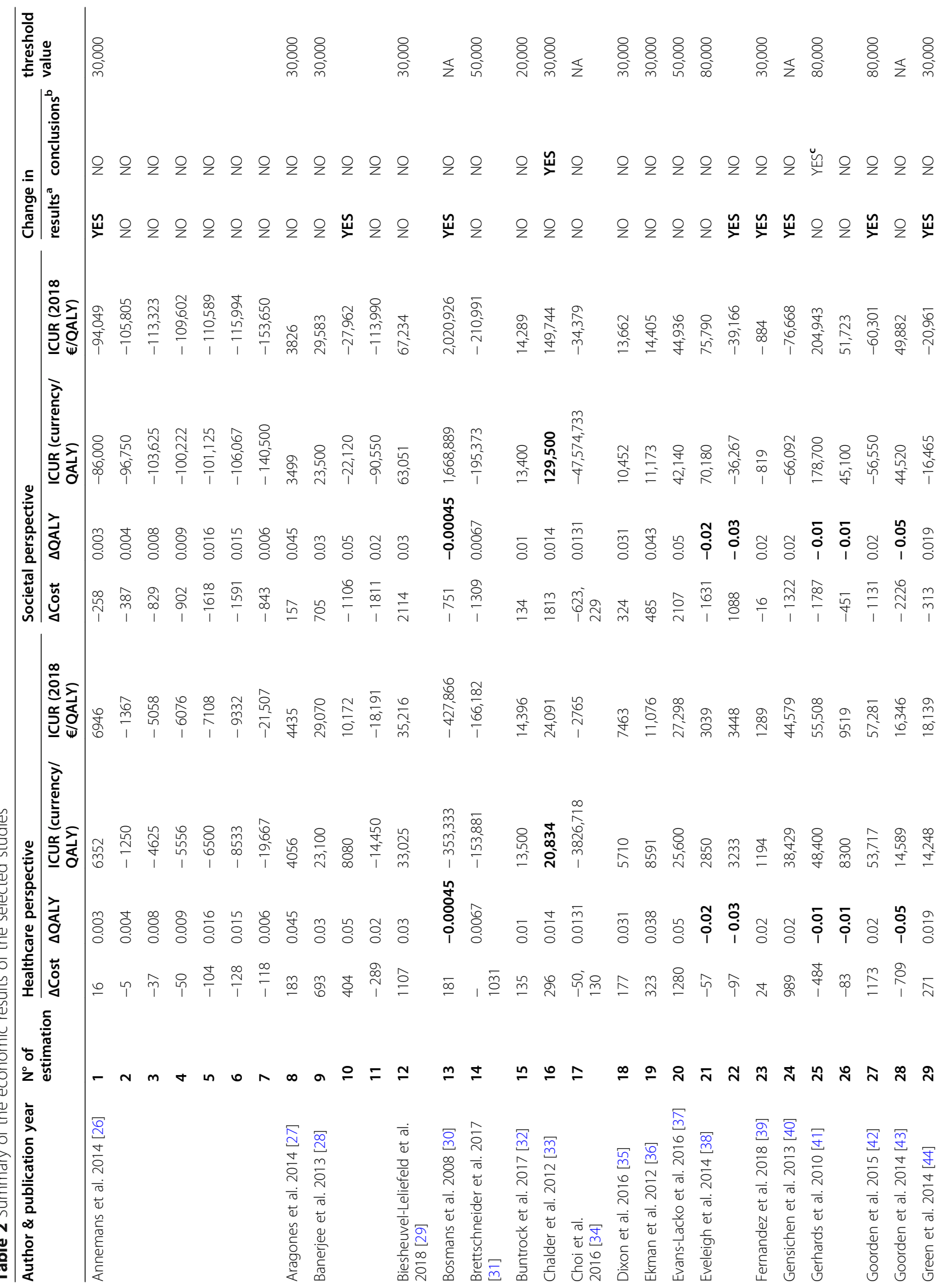




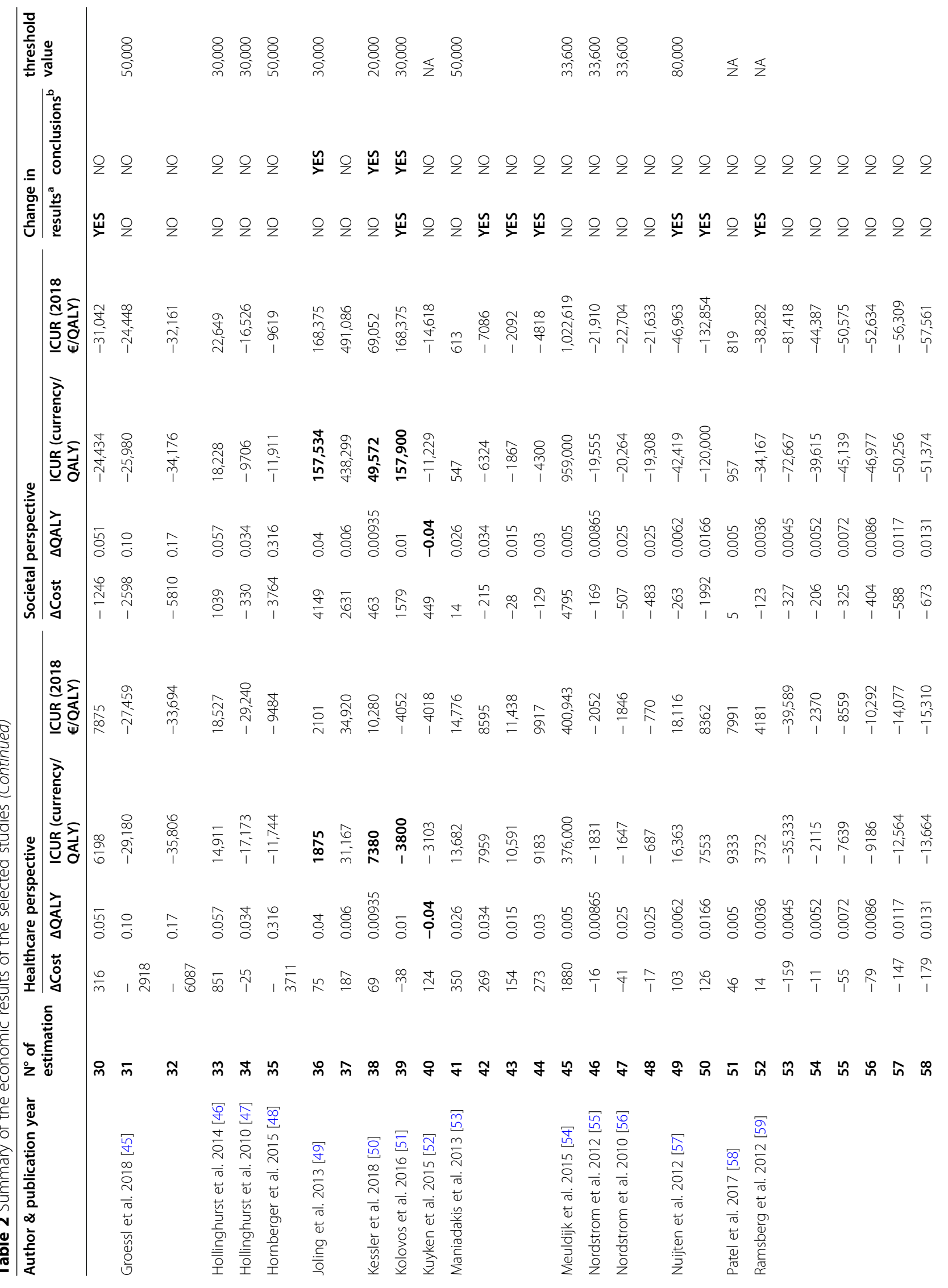




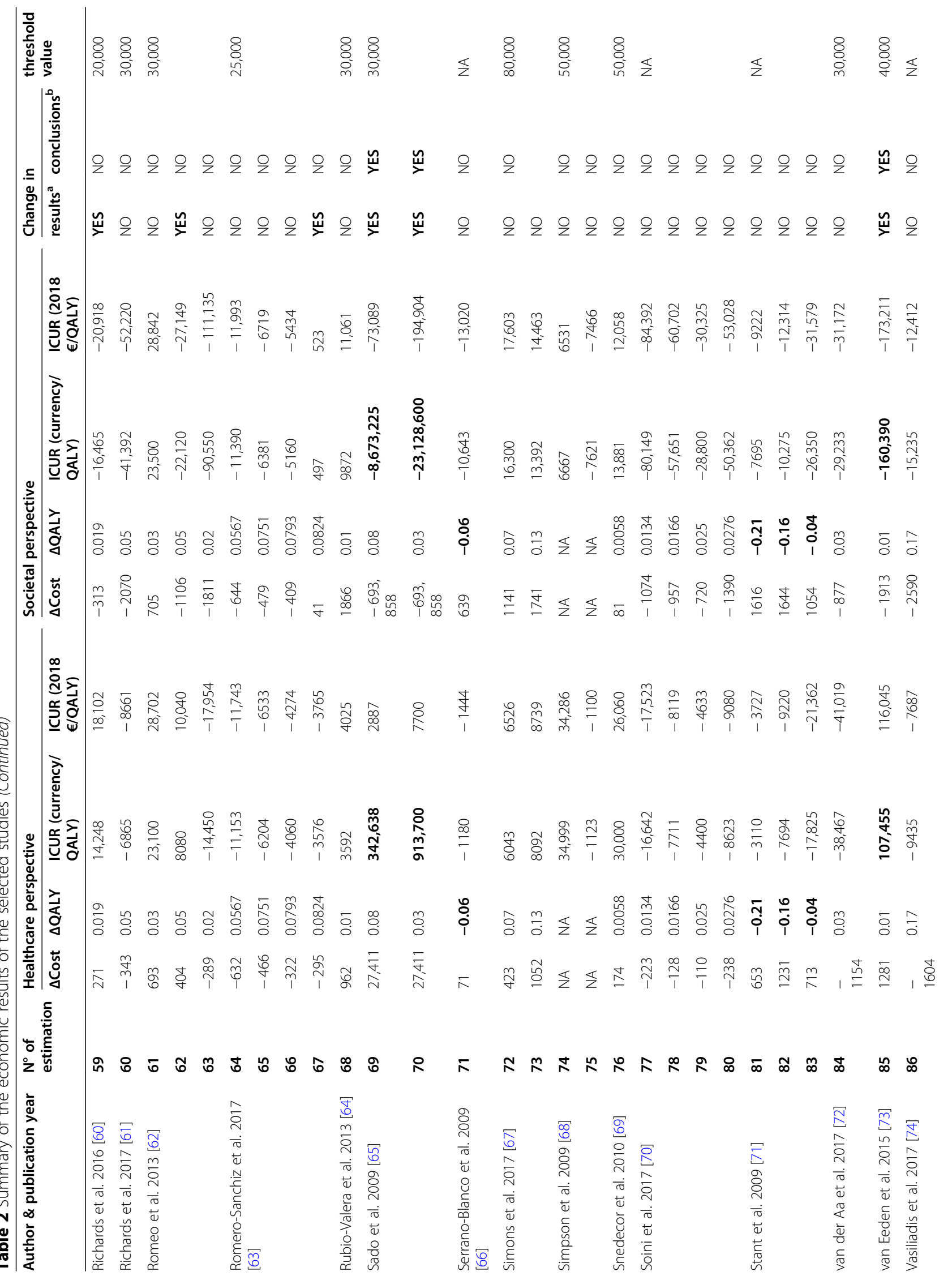




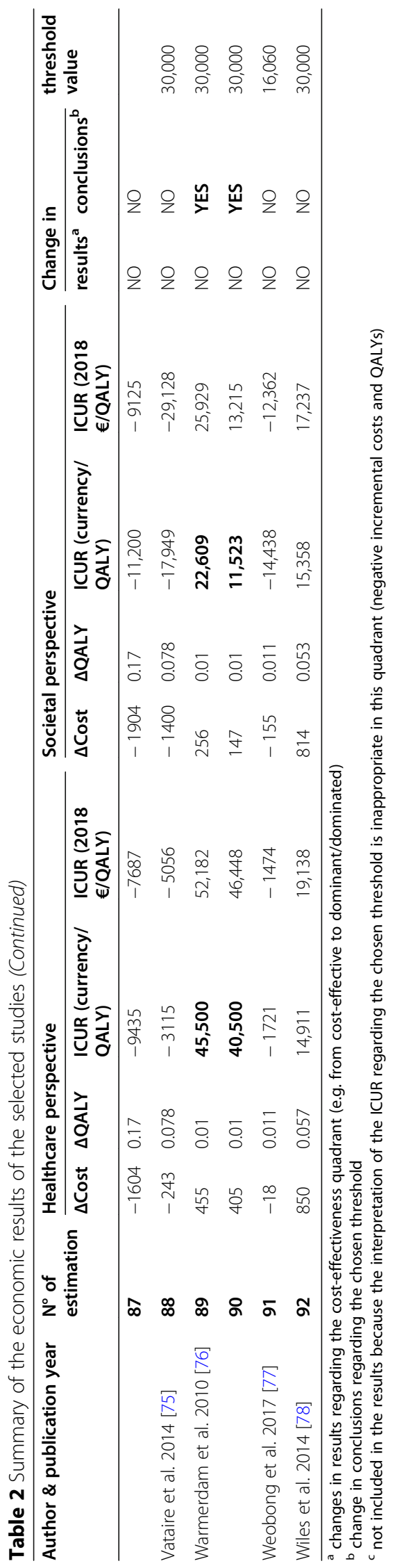




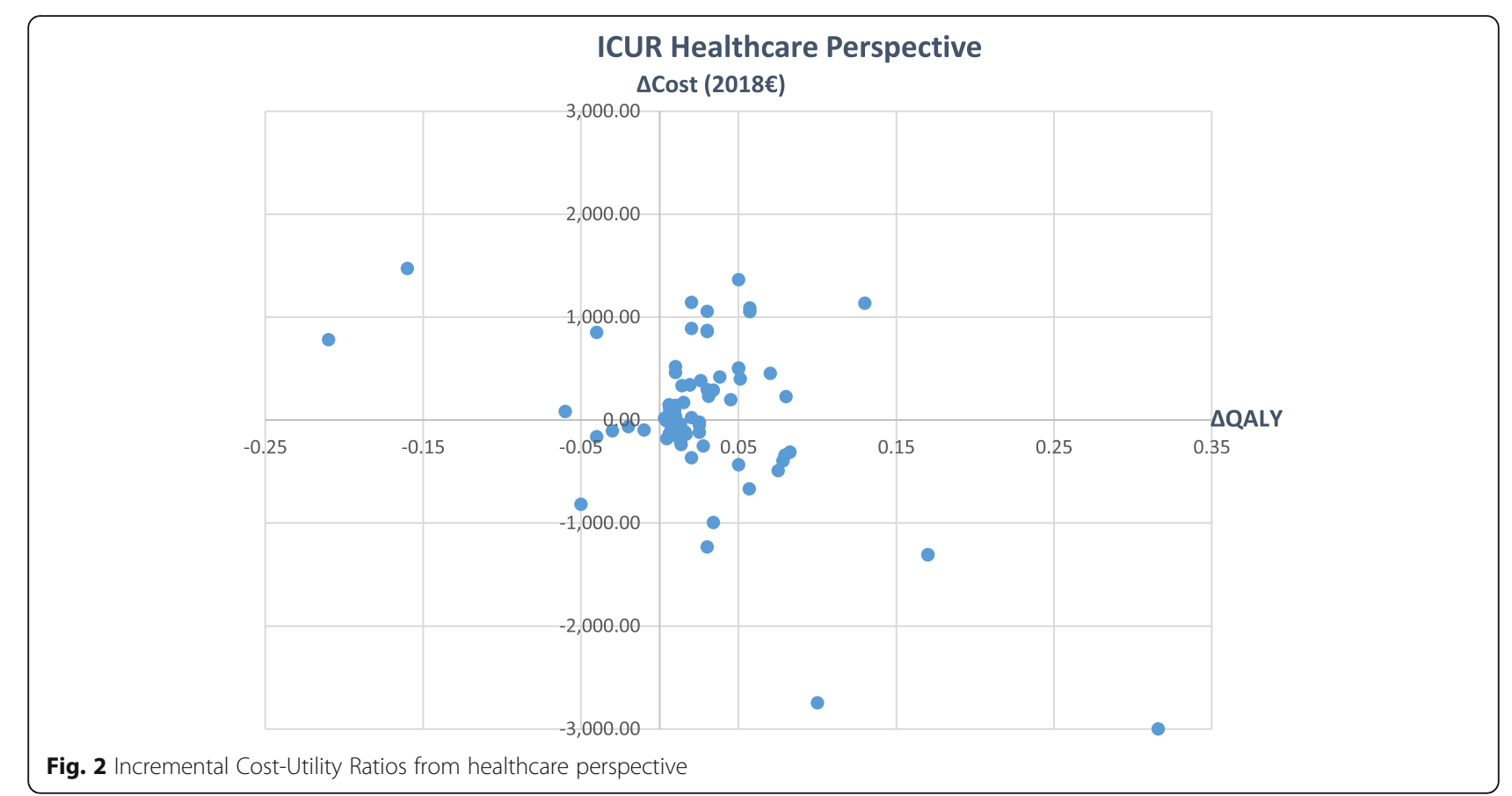

\section{Discussion}

To the best of our knowledge, this is the first review that examines CUA-studies depending on the change in results by including or excluding societal costs (productivity losses and/or informal care costs) in the field of depression, which might even lead to changes in conclusions. Concretely, our results suggest that when societal costs were considered, some of the economic evaluations carried out in depression changed their conclusions/ recommendations, as well as their results. More precisely, of the 92 economic evaluations coming from the 53 articles identified, 22 estimations changed their results regarding the cost-effectiveness quadrant when a societal perspective was included, while 9 estimations changed their conclusions in the decision-making regarding the chosen threshold. In fact, five economic evaluations became cost-effective (three of these single results became dominant) when societal costs were

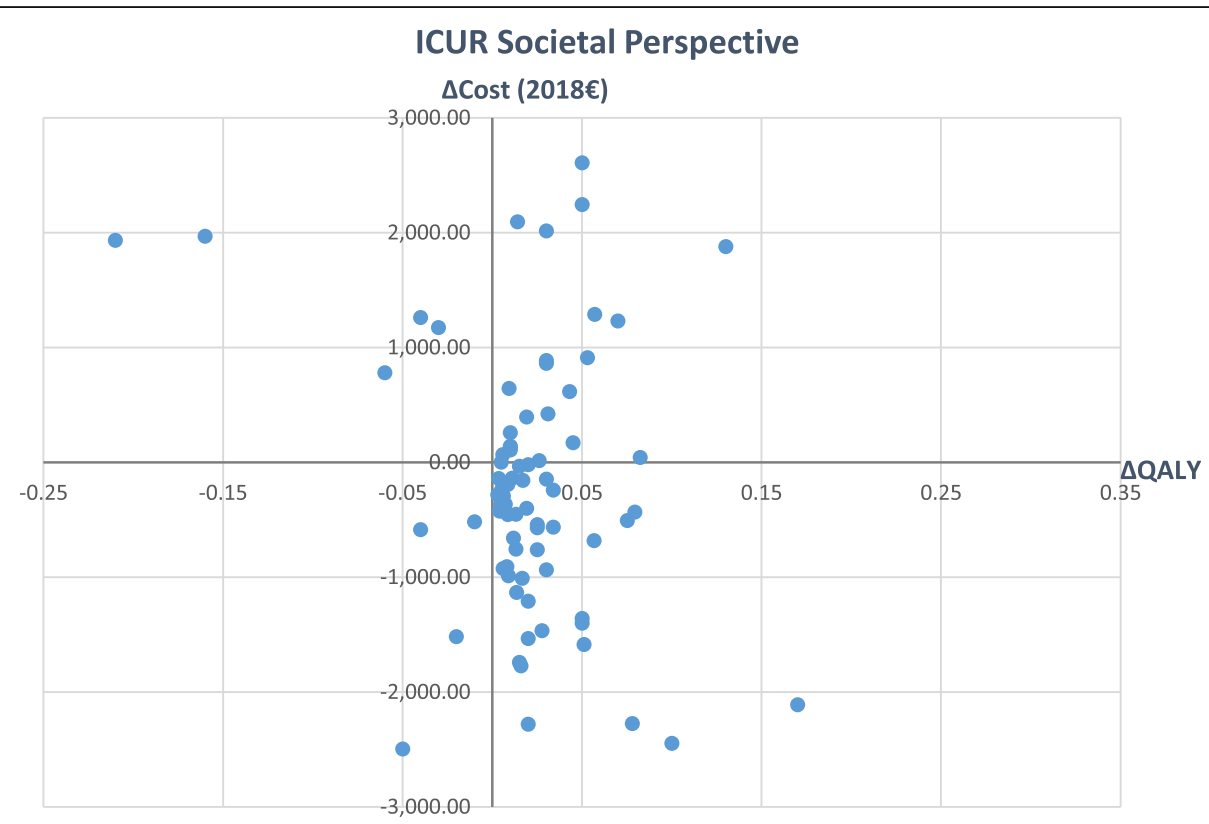

Fig. 3 Incremental Cost-Utility Ratios from societal perspective 
included, compared to the analysis which only included healthcare costs. However, in another four estimations the opposite result was found: these interventions were no longer cost-effective after the inclusion of societal costs. Furthermore, twelve economic evaluations changed from being below the threshold to dominate the standard of care or other comparators when the societal perspective was taken into account.

However, it should be noted that the estimations which calculated negative QALYs were limitedly included in the appraisal of the relevance of societal costs in depression. In fact, economic discussions about the appropriateness of the interpretation of incremental cost-utility or cost-effectiveness results are growing increasingly [79-81]. Especially in the case of negative health effects and lower costs, the ratio is positive as well as when observing positive incremental costs and QALYs. Then, results of Incremental Cost-Effectiveness Ratios in quadrant one and three are both positive but with a very different meaning. Considering the included article of Gerhards et al. the reported ICUR might lead to false conclusions without taking into account the underlying differences in costs and QALYs [41]. Alternative approaches like the net-monetary benefit analysis can help decision makers to overcome these pitfalls [82]. Otherwise the results would lead to the conclusion that including societal costs change results in an opposite way [83]. Even though the inclusion of societal costs changed the recommendations derived from the economic evaluations only in a low number of cases, the importance of revealing potential savings in terms of costs that affect not only the healthcare system but also the society as a whole should be considered.

Nevertheless, even though there are no previous studies that have performed such analysis in the field of depression, and therefore, no direct comparison could be done, the results obtained are in line with those in previous papers in which the authors aimed to analyse the role played by societal costs in economic evaluations in different therapeutic areas [22, 84-86]. Particularly, the consideration of productivity losses could alter the decisions regarding reimbursement of expensive drugs in almost one-third of the cases [85]. In fact, it seems that, depending on the patient's profile, the type of societal costs included (productivity losses and/or informal care costs) might vary. In the case of depression, due to the profile of such populations where the mean age of onset ranges from 24 to 35 years of age, and where productivity losses might have a higher weight within the economic impact of such a disease [74, 75], it is more common to include only productivity losses in CUAs than taking into account informal care or both types of societal costs [87]. Thus, almost $94 \%$ of the economic evaluations in mental and behavioural disorders that include the societal perspective solely considered productivity losses as societal costs only, while informal care costs were only taken into account in $29 \%$ of those evaluations with a societal point of view. Moreover, it was striking that productivity losses were mostly based on absenteeism and less often on presenteeism or both aspects, even though there is sufficient evidence of the existence of presenteeism in depressive disorders [76, 77]. Actually, it has been estimated that presenteeism costs are five to ten times higher than productivity losses due to absenteeism among people with depression, with differences across age groups, educational level and countries being observed [88]. In addition, the relevance of the different approaches to estimate productivity losses could be doubtful, especially in case of narrower time frames. Almost three-quarters of the articles used a time horizon of 1 year or less whilst differences in absenteeism, depending on the approach to be used, are hard to see during such short periods of time. A 5-year horizon analysis showed, in fact, that absenteeism costs were largely increasing after those 5 years, with additional worse health outcomes among absenteeism reporters than presenteeism ones [89].

Regarding the role of informal caregivers, previous studies proved that the impact of informal care costs differed between studies, depending mainly on the disease considered [22, 84, 86]. These papers evidences the fact that informal care costs were only present in one of the economic evaluations considered, making visible that the role played by non-professional care costs in economic evaluations of depression are not quite frequent. However, there is a study which demonstrated that informal care costs could be quite relevant in the field of depression [46]. More precisely, this study, which changed from being cost-effective to rise above the threshold by including societal costs, had the aim of implementing a preventive intervention for caregivers of dementia patients to minimize their risk of developing a depressive disorder. The CUA of these family meetings includes QALYs as well as direct and indirect costs of caregivers and patients. Since the differences in QALYs were very small and informal care costs represented by far the largest contributor to total costs, it is not surprising that the societal perspective led to different results. Therefore, it should be taken into account that interventions for depression could also affect the family caregivers' health and, in this case, costs and QALYs of caregivers should be considered in economic evaluations. In this sense, the societal perspective demands to incorporate not only societal costs but also effects on the health of caregivers, as well as other spill-over effects [90-94].

Another relevant aspect that should be highlighted is that costs due to (attempted) suicide were merely included in three out of the 53 studies, although it is 
known that the risk for suicide in depressed patients is much higher than in the general population [78]. The risk of suicide is closely related to social stigmatization of persons with depression, which remained fully unconsidered in the identified literature of this review [9, 7982]. Therefore, due to the importance of such factor in populations with depression and its economic impact on this disease, further economic evaluations should include these cost components so as not to underestimate the real economic consequences of depression. For this purpose, economic evaluations should consider broader time horizons than the ones which are commonly used in this field.

CUAs of interventions for people suffering from depressive disorders include not only the relevant costs but also the estimated QALYs. Existing literature remarks challenges for using the QALY approach in the field of mental health. Although generic instruments seem to be able to reflect the impact of common conditions such as mild to moderate depression, there are general concerns regarding the measurement of Health-related quality of life (HRQoL) in different groups of patients [95]. There is a perceived need for improved instruments that measure health-related quality of life so that QALYs appropriately reflect the pain, suffering, and limitations experienced by people with mental illness [96]. This would help to better capture the effects of the interventions being evaluated. Hence, the reported incremental QALYs may fail to capture the interventions effect and therefore lead to inaccurate ICURs. In addition to the aspects mentioned above, different degrees of severity of depressive disorders can affect the results of economic evaluations. Thus, the societal perspective may be more relevant in case of severe depression, because of potentially higher costs due to presenteeism and absenteeism $[97,98]$. As the extent of the disease is not always reported by the authors of the underlying studies and the current review focusses especially on the methodological issues of the involvement of societal costs in economic evaluations, this factor was not included in the analysis.

A few limitations of this review should be mentioned. First, several studies showed inconsistencies between the results described in text and tables. Moreover, some analyses were not fully consistent with the methods. In this case, it was not possible to include every single result stated in the selected studies. Due to the heterogeneity in the SA, we only took into consideration the results reported in the main analysis, leaving out the figures reported in the SA. Secondly, the methods applied in the studies varied widely in terms of time horizon and measurement of costs and QALYs. Some limitations refer to limited time resources. Although the initial search resulted in a large number of 1273 studies, it could have been reasonable to expand the timeframe and to extend the literature search to another database. However, as previous studies show, Tufts CEA registry ensures a more accurate search [99]. In this case, 1263 articles were found from PubMed and 1273 from Tufts, getting 10 additional articles from this registry. Limited time resources even restricted capabilities to contact the authors in case of incomplete or misleading information as well as the implementation of an additional quality assessment (e.g. the Consensus on Health Economic Criteria (CHEC)-list [100]). Therefore, the high heterogeneity and variability of the methods applied in the different economic evaluations might be considered when interpreting the results obtained.

\section{Conclusion}

This study contributes to the existing literature by analysing whether the perspective (healthcare payer/provider or societal) of a CUA in the field of depression alters the results and conclusions of the evaluation. Our findings suggest that in some of the studies the inclusion of societal costs of depression leads to substantial changes in both results and conclusions, although wide methodological variations have also been observed. Thus, several analyses led to different conclusions when the intervention was evaluated from a societal compared to a healthcare payer perspective. The results revealed potential savings as well as increases from the evaluated interventions when such costs were included. However, and in purpose to improve comparability, economic evaluations should ideally consider the healthcare as well as the societal perspective leading to more appropriate recommendations. Additionally, future research should consistently follow established guidelines (e.g. CHEERS statement [101]) by reporting all relevant cost components as well as the methods of measurement. In brief, an issue that this paper highlights, is the need for considering the societal perspective when conceptualizing economic evaluations, especially among populations with depression where productivity losses could represent an important weight of its economic impact. Therefore, not considering such effect might lead to an inefficient allocation of resources when designing policies in such target populations.

\section{Abbreviations \\ AE: Adverse events; CEA: Cost-Effectiveness Analysis; CUA: Cost-Utility Analysis; GP: General practitioner; ICUR: Incremental Cost-Utility Ratio; QALY: Quality-adjusted life year; RCT: Randomized controlled trial; SA: Sensitivity analysis}

\section{Acknowledgements \\ Not applicable.}

\section{Authors' contributions}

All authors developed the literature search. LP, BR and IA performed the literature search and title-abstract screening. JD and LH completed literature search and did the data-extraction. LP and BR did the double check revision. $J D$ and LH undertook the synthesis and made a first draft of this manuscript. 
All authors contributed to the drafting and revising of the manuscript. The authors read and approved the final manuscript.

\section{Funding}

This project has received funds from the European Union's Horizon 2020 research and innovation programme under grant agreement No 779312. We acknowledge support for the Article Processing Charge by the Deutsche Forschungsgemeinschaft and the Open Access Publication Fund of Bielefeld University. Open Access funding enabled and organized by Projekt DEAL.

\section{Availability of data and materials}

The data analysed during the current study are available from the corresponding authors on request.

\section{Ethics approval and consent to participate}

Not applicable.

\section{Consent for publication}

Not applicable.

\section{Competing interests}

The authors declare that they have no competing interests.

\section{Author details}

${ }^{1}$ AG 5 - Department of Health Economics and Health Care Management, Bielefeld University, School of Public Health, Universitaetsstrasse 25, 33615

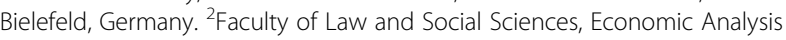
Department, Research Group in Economics and Health, University of Castilla-La Mancha, Cobertizo San Pedro Mártir, S/N, 45002 Toledo, Spain. ${ }^{3}$ Faculty of Technology and Science, University Camilo José Cela, Urb. Villafranca del Castillo, Calle Castillo de Alarcón, 49, 28692 Villanueva de la Cañada, Madrid, Spain. ${ }^{4}$ Faculty of Social Science, Economic Analysis and Finance Department, Research Group in Economics and Health, University of Castilla-La Mancha, Avda. Real Fábrica s/n, Talavera de la Reina, 45600 Toledo, Spain. ${ }^{5}$ Faculty of Health Science, Research Group in Economics and Health, University of Castilla-La Mancha, Av. Real Fábrica de Sedas, s/n, Talavera de la Reina, 45600 Toledo, Spain.

Received: 6 July 2020 Accepted: 7 September 2020 Published online: 22 September 2020

\section{References}

1. WHO. Depression and Other Common Mental Disorders: Global Health Estimates. Geneva: World Health Organization; 2017. Licence: CC BYNC-SA 3. 0 IGO.

2. Disease GBD, Injury I, Prevalence C. Global, regional, and national incidence, prevalence, and years lived with disability for 354 diseases and injuries for 195 countries and territories, 1990-2017: a systematic analysis for the global burden of Disease study 2017. Lancet (London, England). 2018;392(10159): $1789-858$.

3. Roehrig C. Mental disorders top the list of the Most costly conditions in the United States: $\$ 201$ billion. Health affairs (Project Hope). 2016;35(6):1130-5.

4. Trautmann S, Rehm J, Wittchen H-U. The economic costs of mental disorders: do our societies react appropriately to the burden of mental disorders? EMBO Rep. 2016;17(9):1245-9.

5. Mojtabai R, Olfson M, Han B. National Trends in the Prevalence and treatment of depression in adolescents and young adults. Pediatrics. 2016; 138(6):e20161878.

6. Foundation WHOaCG. Social determinants of mental health. Geneva: World Health Organization; 2014.

7. Lerner D, Henke RM. What does research tell us about depression, job performance, and work productivity? J Occup Environ Med. 2008;50(4):40110

8. Ravindran AV, Balneaves LG, Faulkner G, Ortiz A, Mclntosh D, Morehouse RL, Ravindran L, Yatham LN, Kennedy SH, Lam RW, et al. Canadian Network for Mood and Anxiety Treatments (CANMAT) 2016 Clinical guidelines for the Management of Adults with major depressive disorder: section 5. Complementary and alternative medicine treatments. Can J Psychiatry Rev. 2016;61(9):576-87.
9. Gregory E. Simon, Marcelo Fleck, Ramona Lucas, Donald M. Bushnell, Prevalence and Predictors of Depression Treatment in an International Primary Care Study. Am J Psychiatr 2004, 161(9):1626-1634.

10. Kohls E, Coppens E, Hug J, Wittevrongel E, Van Audenhove C, Koburger N, Arensman E, Székely A, Gusmão R, Hegerl U. Public attitudes toward depression and help-seeking: impact of the OSPI-Europe depression awareness campaign in four European regions. J Affect Disord. 2017;217: 252-9.

11. Roeloffs C, Sherbourne C, Unützer J, Fink A, Tang L, Wells KB. Stigma and depression among primary care patients. Gen Hosp Psychiatry. 2003;25(5): $311-5$.

12. Sharac J, McCrone P, Clement S, Thornicroft G. The economic impact of mental health stigma and discrimination: a systematic review. Epidemiol Psichiatr Soc. 2010;19(3):223-32.

13. McCrone $\mathrm{P}$, Knapp M, Henri M, McDaid D. The economic impact of initiatives to reduce stigma: demonstration of a modelling approach. Epidemiol Psichiatr Soc. 2010;19(2):131-9.

14. Coretti S, Rumi F, Cicchetti A. The social cost of major depression. A Systematic Review. Rev Eur Stud. 2019;11:73.

15. Sobocki $P$, Jönsson $B$, Angst J, Rehnberg C. Cost of depression in Europe. $J$ Ment Health Policy Econ. 2006;9(2):87-98.

16. von Knorring L, Akerblad AC, Bengtsson F, Carlsson A, Ekselius L. Cost of depression: effect of adherence and treatment response. Eur Psychiatry. 2006;21(6):349-54

17. Mihalopoulos C, Vos T. Cost-effectiveness of preventive interventions for depressive disorders: an overview. Expert Rev Pharmacoecon Outcomes Res. 2013;13(2):237-42

18. Khoo AL, Zhou HJ, Teng M, Lin L, Zhao YJ, Soh LB, Mok YM, Lim BP, Gwee KP. Network meta-analysis and cost-effectiveness analysis of new generation antidepressants. CNS Drugs. 2015;29(8):695-712.

19. Antonanzas F, Rodríguez-lbeas R, Juárez C, Hutter F, Lorente R, Pinillos M. Transferability indices for health economic evaluations: methods and applications. Health Econ. 2009;18(6):629-43.

20. Mandrik O, Knies S, Kalo Z, Severens JL. Reviewing TRANSFERABILITY in economic evaluations originating from EASTERN Europe. Int J Technol Assess Health Care. 2015:31(6):434-41.

21. Oliva J, Brosa M, Espín J, Figueras M, Trapero M, Key4Value-Grupo I. Controversial issues in economic evaluation (I): perspective and costs of health care interventions. Rev Esp Salud Publica. 2015;89(1):5-14.

22. Peña-Longobardo LM, Rodríguez-Sánchez B, Oliva-Moreno J, Aranda-Reneo I, López-Bastida J. How relevant are social costs in economic evaluations? The case of Alzheimer's disease. Eur J Health Econ. 2019;20(8):1207-36.

23. Tufts Medical Center $\mathrm{CftEoVaRiH}$ : The cost-effectiveness analysis registry. www.cearegistry.org. Accessed 22 Oct 2019.

24. EUROSTAT. Harmonised index of consumer prices (HICP). In: Statistical Office of the European Communities; 2019.

25. Drummond MFS, Mark J, Claxton K, Stoddart GL, Torrance GW. Methods for the economic evaluation of health care programmes. 4th ed. Oxford: Oxford University Press; 2015.

26. Annemans L, Brignone M, Druais S, De Pauw A, Gauthier A, Demyttenaere K Cost-effectiveness analysis of pharmaceutical treatment options in the firstline management of major depressive disorder in Belgium. PharmacoEconomics. 2014;32(5):479-93.

27. Aragones E, Lopez-Cortacans G, Sanchez-Iriso E, Pinol JL, Caballero A, SalvadorCarulla L, Cabases J. Cost-effectiveness analysis of a collaborative care programme for depression in primary care. J Affect Disord. 2014;159:85-93.

28. Banerjee S, Hellier J, Romeo R, Dewey M, Knapp M, Ballard C, Baldwin R, Bentham P, Fox C, Holmes C, et al. Study of the use of antidepressants for depression in dementia: the HTA-SADD trial--a multicentre, randomised, double-blind, placebo-controlled trial of the clinical effectiveness and costeffectiveness of sertraline and mirtazapine. Health Technol Assess (Winchester, England). 2013;17(7):1-166.

29. Biesheuvel-Leliefeld KEM, Bosmans JE, Dijkstra-Kersten SMA, Smit F, Bockting CLH, van Schaik DJF, van Marwijk HWJ, van der Horst HE. A supported selfhelp for recurrent depression in primary care; an economic evaluation alongside a multi-center randomised controlled trial. PLoS One. 2018;13(12): e0208570

30. Bosmans JE, Hermens ML, de Bruijne MC, van Hout HP, Terluin B, Bouter LM, Stalman WA, van Tulder MW. Cost-effectiveness of usual general practitioner care with or without antidepressant medication for patients with minor or mild-major depression. J Affect Disord. 2008;111(1):106-12. 
31. Brettschneider C, Kohlmann S, Gierk B, Lowe B, Konig HH. Depression screening with patient-targeted feedback in cardiology: the costeffectiveness of DEPSCREEN-INFO. PLoS One. 2017;12(8):e0181021.

32. Buntrock C, Berking M, Smit F, Lehr D, Nobis S, Riper H, Cuijpers P, Ebert D. Preventing depression in adults with subthreshold depression: healtheconomic evaluation alongside a pragmatic randomized controlled trial of a web-based intervention. J Med Internet Res. 2017;19(1):e5.

33. Chalder M, Wiles NJ, Campbell J, Hollinghurst SP, Searle A, Haase AM, Taylor $\mathrm{AH}$, Fox KR, Baxter H, Davis M, et al. A pragmatic randomised controlled trial to evaluate the cost-effectiveness of a physical activity intervention as a treatment for depression: the treating depression with physical activity (TREAD) trial. Health Technol Assess (Winchester, England). 2012;16(10):1-164 iii-iv.

34. Choi SE, Brignone M, Cho SJ, Jeon HJ, Jung R, Campbell R, Francois C, Milea D. Cost-effectiveness of vortioxetine versus venlafaxine (extended release) in the treatment of major depressive disorder in South Korea. Expert Rev Pharmacoecon Outcomes Res. 2016;16(5):629-38.

35. Dixon P, Hollinghurst S, Edwards L, Thomas C, Foster A, Davies B, Gaunt D, Montgomery AA, Salisbury C. Cost-effectiveness of telehealth for patients with depression: evidence from the Healthlines randomised controlled trial. BJPsych Open. 2016;2(4):262-9.

36. Ekman $M$, Lindgren $P$, Miltenburger $C$, Meier $G$, Locklear JC, Chatterton ML. Cost effectiveness of quetiapine in patients with acute bipolar depression and in maintenance treatment after an acute depressive episode. PharmacoEconomics. 2012;30(6):513-30.

37. Evans-Lacko S, Koeser L, Knapp M, Longhitano C, Zohar J, Kuhn K. Evaluating the economic impact of screening and treatment for depression in the workplace. Eur Neuropsychopharmacol. 2016;26(6):1004-13.

38. Eveleigh R, Grutters J, Muskens E, Oude Voshaar R, van Weel C, Speckens A, Lucassen P. Cost-utility analysis of a treatment advice to discontinue inappropriate long-term antidepressant use in primary care. Fam Pract. 2014;31(5):578-84.

39. Fernandez A, Mendive JM, Conejo-Ceron S, Moreno-Peral P, King M Nazareth I, Martin-Perez C, Fernandez-Alonso C, Rodriguez-Bayon A, Aiarzaguena JM, et al. A personalized intervention to prevent depression in primary care: cost-effectiveness study nested into a clustered randomized trial. BMC Med. 2018;16(1):28.

40. Gensichen J, Petersen JJ, Von Korff M, Heider D, Baron S, Konig J, Freytag A, Krauth C, Gerlach FM, Konig HH. Cost-effectiveness of depression case management in small practices. Br J Psychiatry. 2013;202:441-6.

41. Gerhards SA, de Graaf LE, Jacobs LE, Severens JL, Huibers MJ, Arntz A, Riper H, Widdershoven G, Metsemakers JF, Evers SM. Economic evaluation of online computerised cognitive-behavioural therapy without support for depression in primary care: randomised trial. Br J Psychiatry. 2010;196(4):310-8.

42. Goorden M, Huijbregts KM, van Marwijk HW, Beekman AT, van der FeltzCornelis CM, Hakkaart-van Roijen L. Cost-utility of collaborative care for major depressive disorder in primary care in the Netherlands. J Psychosom Res. 2015;79(4):316-23

43. Goorden M, Vlasveld MC, Anema JR, van Mechelen W, Beekman AT, Hoedeman R, van der Feltz-Cornelis CM, Hakkaart-van Roijen L. Cost-utility analysis of a collaborative care intervention for major depressive disorder in an occupational healthcare setting. J Occup Rehabil. 2014;24(3):555-62.

44. Green C, Richards DA, Hill JJ, Gask L, Lovell K, Chew-Graham C, Bower P, Cape J, Pilling S, Araya R, et al. Cost-effectiveness of collaborative care for depression in UK primary care: economic evaluation of a randomised controlled trial (CADET). PLoS One. 2014;9(8):e104225.

45. Groessl EJ, Tally SR, Hillery N, Maciel A, Garces JA. Cost-effectiveness of a Pharmacogenetic test to guide treatment for major depressive disorder. J Manag Care Spec Pharm. 2018;24(8):726-34.

46. Hollinghurst S, Carroll FE, Abel A, Campbell J, Garland A, Jerrom B, Kessler D, Kuyken W, Morrison J, Ridgway N, et al. Cost-effectiveness of cognitivebehavioural therapy as an adjunct to pharmacotherapy for treatmentresistant depression in primary care: economic evaluation of the CoBalT trial. Br J Psychiatry. 2014;204(1):69-76.

47. Hollinghurst S, Peters TJ, Kaur S, Wiles N, Lewis G, Kessler D. Costeffectiveness of therapist-delivered online cognitive-behavioural therapy for depression: randomised controlled trial. Br J Psychiatry. 2010;197(4):297-304.

48. Hornberger J, Li Q, Quinn B. Cost-effectiveness of combinatorial pharmacogenomic testing for treatment-resistant major depressive disorder patients. Am J Manag Care. 2015;21(6):e357-65.

49. Joling KJ, Bosmans JE, van Marwijk HW, van der Horst HE, Scheltens P, MacNeil Vroomen JL, van Hout HP. The cost-effectiveness of a family meetings intervention to prevent depression and anxiety in family caregivers of patients with dementia: a randomized trial. Trials. 2013;14:305.

50. Kessler D, Burns A, Tallon D, Lewis G, MacNeill S, Round J, Hollingworth W, Chew-Graham C, Anderson I, Campbell J, et al. Combining mirtazapine with SSRIs or SNRIs for treatment-resistant depression: the MIR RCT. Health Technol Assess (Winchester, England). 2018;22(63):1-136.

51. Kolovos S, Kenter RM, Bosmans JE, Beekman AT, Cuijpers P, Kok RN, van Straten A. Economic evaluation of internet-based problem-solving guided self-help treatment in comparison with enhanced usual care for depressed outpatients waiting for face-to-face treatment: a randomized controlled trial. J Affect Disord. 2016;200:284-92.

52. Kuyken W, Hayes R, Barrett B, Byng R, Dalgleish T, Kessler D, Lewis G, Watkins E, Morant N, Taylor RS, et al. The effectiveness and costeffectiveness of mindfulness-based cognitive therapy compared with maintenance antidepressant treatment in the prevention of depressive relapse/recurrence: results of a randomised controlled trial (the PREVENT study). Health Technol Assess (Winchester, England). 2015;19(73):1-124.

53. Maniadakis N, Kourlaba G, Mougiakos T, Chatzimanolis I, Jonsson L. Economic evaluation of agomelatine relative to other antidepressants for treatment of major depressive disorders in Greece. BMC Health Serv Res. 2013;13:173.

54. Meuldijk D, Carlier IV, van Vliet IM, van Hemert AM, Zitman FG, van den Akker-van Marle ME. Economic evaluation of concise cognitive Behavioural therapy and/or pharmacotherapy for depressive and anxiety disorders. J Ment Health Policy Econ. 2015;18(4):175-83.

55. Nordstrom G, Danchenko N, Despiegel N, Marteau F. Cost-effectiveness evaluation in Sweden of escitalopram compared with venlafaxine extendedrelease as first-line treatment in major depressive disorder. Value Health. 2012;15(2):231-9.

56. Nordstrom G, Despiegel N, Marteau F, Danchenko N, Maman K. Cost effectiveness of escitalopram versus SNRIs in second-step treatment of major depressive disorder in Sweden. J Med Econ. 2010;13(3):516-26.

57. Nuijten MJ, Brignone M, Marteau F, den Boer JA, Hoencamp E. Costeffectiveness of escitalopram in major depressive disorder in the Dutch health care setting. Clin Ther. 2012;34(6):1364-78.

58. Patel V, Weobong B, Weiss HA, Anand A, Bhat B, Katti B, Dimidjian S, Araya $R$, Hollon SD, King M, et al. The Healthy Activity Program (HAP), a lay counsellor-delivered brief psychological treatment for severe depression, in primary care in India: a randomised controlled trial. Lancet (London, England). 2017;389(10065):176-85.

59. Ramsberg J, Asseburg C, Henriksson M. Effectiveness and cost-effectiveness of antidepressants in primary care: a multiple treatment comparison metaanalysis and cost-effectiveness model. PLoS One. 2012;7(8):e42003.

60. Richards DA, Bower P, Chew-Graham C, Gask L, Lovell K, Cape J, Pilling S, Araya R, Kessler D, Barkham M, et al. Clinical effectiveness and costeffectiveness of collaborative care for depression in UK primary care (CADE T): a cluster randomised controlled trial. Health Technol Assess (Winchester, England). 2016;20(14):1-192.

61. Richards DA, Rhodes S, Ekers D, McMillan D, Taylor RS, Byford S, Barrett B, Finning K, Ganguli P, Warren F, et al. Cost and Outcome of BehaviouRal Activation (COBRA): a randomised controlled trial of behavioural activation versus cognitive-behavioural therapy for depression. Health Technol Assess (Winchester, England). 2017;21(46):1-366.

62. Romeo R, Knapp M, Hellier J, Dewey M, Ballard C, Baldwin R, Bentham P, Burns A, Fox C, Holmes C, et al. Cost-effectiveness analyses for mirtazapine and sertraline in dementia: randomised controlled trial. Br Journal Psychiatry. 2013;202:121-8.

63. Romero-Sanchiz P, Nogueira-Arjona R, Garcia-Ruiz A, Luciano JV, Garcia Campayo J, Gili M, Botella C, Banos R, Castro A, Lopez-Del-Hoyo Y, et al. Economic evaluation of a guided and unguided internet-based CBT intervention for major depression: results from a multi-center, three-armed randomized controlled trial conducted in primary care. PLoS One. 2017; 12(2):e0172741.

64. Rubio-Valera M, Bosmans J, Fernandez A, Penarrubia-Maria M, March M, Trave P, Bellon JA, Serrano-Blanco A. Cost-effectiveness of a community pharmacist intervention in patients with depression: a randomized controlled trial (PRODEFAR study). PLoS One. 2013;8(8):e70588.

65. Sado M, Knapp M, Yamauchi K, Fujisawa D, So M, Nakagawa A, Kikuchi T, Ono Y. Cost-effectiveness of combination therapy versus antidepressant therapy for management of depression in Japan. Aust N Z J Psychiatry. 2009;43(6):539-47. 
66. Serrano-Blanco A, Suarez D, Pinto-Meza A, Penarrubia MT, Haro JM. Fluoxetine and imipramine: are there differences in cost-utility for depression in primary care? J Eval Clin Pract. 2009;15(1):195-203.

67. Simons CJP, Drukker M, Evers S, van Mastrigt G, Hohn P, Kramer I, Peeters F, Delespaul P, Menne-Lothmann C, Hartmann JA, et al. Economic evaluation of an experience sampling method intervention in depression compared with treatment as usual using data from a randomized controlled trial. BMC Psychiatry. 2017;17(1):415.

68. Simpson KN, Welch MJ, Kozel FA, Demitrack MA, Nahas Z. Cost-effectiveness of transcranial magnetic stimulation in the treatment of major depression: a health economics analysis. Adv Ther. 2009;26(3):346-68.

69. Snedecor SJ, Botteman MF, Schaefer K, Sarocco P, Barry N, Pickard AS. Economic outcomes of eszopiclone treatment in insomnia and comorbid major depressive disorder. J Ment Health Policy Econ. 2010;13(1):27-35.

70. Soini E, Hallinen T, Brignone M, Campbell R, Diamand F, Cure S, Aalto-Setala M, Danchenko N, Koponen H, Kolasa K. Cost-utility analysis of vortioxetine versus agomelatine, bupropion SR, sertraline and venlafaxine XR after treatment switch in major depressive disorder in Finland. Expert Rev Pharmacoecon Outcomes Ress. 2017:17(3):293-302.

71. Stant AD, TenVergert EM, Kluiter H, Conradi HJ, Smit A, Ormel J. Costeffectiveness of a psychoeducational relapse prevention program for depression in primary care. J Ment Health Policy Econ. 2009;12(4):195-204.

72. van der Aa HPA, van Rens G, Bosmans JE, Comijs HC, van Nispen RMA. Economic evaluation of stepped-care versus usual care for depression and anxiety in older adults with vision impairment: randomized controlled trial. BMC Psychiatry. 2017;17(1):280.

73. van Eeden M, Kootker JA, Evers SM, van Heugten CM, Geurts AC, van Mastrigt GA. An economic evaluation of an augmented cognitive behavioural intervention vs. computerized cognitive training for post-stroke depressive symptoms. BMC Neurol. 2015;15:266.

74. Vasiliadis HM, Dezetter A, Latimer E, Drapeau M, Lesage A. Assessing the Costs and Benefits of Insuring Psychological Services as Part of Medicare for Depression in Canada. Psychiatr Serv (Washington, DC). 2017;68(9):899-906.

75. Vataire AL, Aballea S, Antonanzas F, Roijen LH, Lam RW, McCrone P, Persson U, Toumi M. Core discrete event simulation model for the evaluation of health care technologies in major depressive disorder. Value Health. 2014; 17(2):183-95.

76. Warmerdam L, Smit F, van Straten A, Riper H, Cuijpers P. Cost-utility and cost-effectiveness of internet-based treatment for adults with depressive symptoms: randomized trial. J Med Internet Res. 2010;12(5):e53.

77. Weobong B, Weiss HA, McDaid D, Singla DR, Hollon SD, Nadkarni A, Park $A L$, Bhat B, Katti B, Anand A, et al. Sustained effectiveness and costeffectiveness of the healthy activity Programme, a brief psychological treatment for depression delivered by lay counsellors in primary care: 12month follow-up of a randomised controlled trial. PLoS Med. 2017;14(9): e1002385.

78. Wiles N, Thomas L, Abel A, Barnes M, Carroll F, Ridgway N, Sherlock S, Turner N, Button K, Odondi L, et al. Clinical effectiveness and costeffectiveness of cognitive behavioural therapy as an adjunct to pharmacotherapy for treatment-resistant depression in primary care: the CoBalT randomised controlled trial. Health Technol Assess (Winchester, England). 2014;18(31):1-167 vii-viii.

79. Hounton S, Newlands D. Applying the net-benefit framework for assessing cost-effectiveness of interventions towards universal health coverage. Cost Effectiveness Resour Allocation. 2012;10(1):8-8.

80. Messori A, Trippoli S. The results of a pharmacoeconomic study: incremental cost-effectiveness ratio versus net monetary benefit. Heart (British Cardiac Society). 2017;103(21):1746.

81. Drummond M, Sculpher M. Common methodological flaws in economic evaluations. Med Care. 2005;43(7):II5-II14.

82. Stinnett AA, Mullahy J. Net Health Benefits: A New Framework for the Analysis of Uncertainty in Cost-Effectiveness Analysis. Med Decis Making. 1998;18(2_suppl):S68-80.

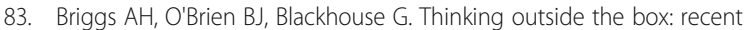
advances in the analysis and presentation of uncertainty in costeffectiveness studies. Annu Rev Public Health. 2002;23(1):377-401.

84. Goodrich K, Kaambwa B, Al-Janabi H. The inclusion of informal care in applied economic evaluation: a review. Value Health. 2012;15(6):975-81.

85. Krol M, Papenburg J, Tan SS, Brouwer W, Hakkaart L. A noticeable difference? Productivity costs related to paid and unpaid work in economic evaluations on expensive drugs. Eur J Health Econ. 2016;17(4):391-402.
86. Krol M, Papenburg J, van Exel J. Does including informal care in economic evaluations matter? A systematic review of inclusion and impact of informal care in cost-effectiveness studies. PharmacoEconomics. 2015;33(2):123-35.

87. Drost RMWA, van der Putten IM, Ruwaard D, Evers SMAA, Paulus ATG. Conceptualizations of the societal perspective within economic evaluations: a systematic review. Int J Technol Assess Health Care. 2017;33(2):251-60.

88. Evans-Lacko S, Knapp M. Global patterns of workplace productivity for people with depression: absenteeism and presenteeism costs across eight diverse countries. Soc Psychiatry Psychiatr Epidemiol. 2016;51(11):1525-37.

89. Cocker F, Nicholson JM, Graves N, Oldenburg B, Palmer AJ, Martin A, Scott J, Venn A, Sanderson K. Depression in working adults: comparing the costs and health outcomes of working when ill. PLoS One. 2014;9(9):e105430.

90. Brouwer WBF. The inclusion of spillover effects in economic evaluations: not an optional extra. PharmacoEconomics. 2019;37(4):451-6.

91. Edwards RT. The inclusion of spillover effects in economic evaluation: a public health economics perspective. PharmacoEconomics. 2019;37(4):6213.

92. Grosse SD, Pike J, Soelaeman R, Tilford JM. Quantifying family spillover effects in economic evaluations: measurement and valuation of informal care time. PharmacoEconomics. 2019;37(4):461-73.

93. Hoefman RJ, van Exel J, Brouwer W. How to include informal care in economic evaluations. PharmacoEconomics. 2013:31(12):1105-19.

94. Lin P-J, D'Cruz B, Leech AA, Neumann PJ, Sanon Aigbogun M, Oberdhan D, Lavelle TA. Family and caregiver spillover effects in cost-utility analyses of Alzheimer's Disease interventions. PharmacoEconomics. 2019;37(4):597-608.

95. Brazier J. Is the EQ-5D fit for purpose in mental health? Br J Psychiatry. 2010;197(5):348-9.

96. Pettitt DARS, Naughton B, Roscoe A, Ramakrishnan A, Ali A, Davis B, Dopson S, Hollander G, Smith JA, Brindley DA, S R. The Limitations of QALY: A Literature Review. J Stem Cell Res Ther. 2016;06(04):334.

97. Ekman M, Granström O, Omérov S, Jacob J, Landén M. The societal cost of depression: evidence from 10,000 Swedish patients in psychiatric care. J Affect Disord. 2013:150(3):790-7.

98. Jain G, Roy A, Harikrishnan V, Yu S, Dabbous O, Lawrence C. Patientreported depression severity measured by the PHQ-9 and impact on work productivity: results from a survey of full-time employees in the United States. J Occup Environ Med. 2013;55(3):252-8.

99. Saret CJ, Winn AN, Shah G, Parsons SK, Lin PJ, Cohen JT, Neumann PJ. Value of innovation in hematologic malignancies: a systematic review of published cost-effectiveness analyses. Blood. 2015;125(12):1866-9.

100. Evers S, Goossens M, de Vet H, van Tulder M, Ament A. Criteria list for assessment of methodological quality of economic evaluations: consensus on health economic criteria. Int J Technol Assess Health Care. 2005;21(2): 240-5.

101. Husereau D, Drummond M, Petrou S, Carswell C, Moher D, Greenberg D, Augustovski F, Briggs AH, Mauskopf J, Loder E, et al. Consolidated health economic evaluation reporting standards (CHEERS) statement. Cost Effectiveness Resour Allocation. 2013;11(1):6.

\section{Publisher's Note}

Springer Nature remains neutral with regard to jurisdictional claims in published maps and institutional affiliations.

Ready to submit your research? Choose BMC and benefit from:

- fast, convenient online submission

- thorough peer review by experienced researchers in your field

- rapid publication on acceptance

- support for research data, including large and complex data types

- gold Open Access which fosters wider collaboration and increased citations

- maximum visibility for your research: over $100 \mathrm{M}$ website views per year

At $\mathrm{BMC}$, research is always in progress.

Learn more biomedcentral.com/submissions 